\title{
African drylands ecosystem changes controlled by soil water
}

Fangli Wei ${ }^{1,2}$, Shuai Wang ${ }^{3 *}$, Bojie Fu ${ }^{1,3}$, Lixin Wang ${ }^{4}$, Yi Y. Liu ${ }^{5,6}, \mathrm{Yan} \mathrm{Li}^{3}$

1. State Key Laboratory of Urban and Regional Ecology, Research Center for EcoEnvironmental Sciences, Chinese Academy of Sciences, Beijing 100085, China

2. University of Chinese Academy of Sciences, Beijing 100049, China

3. State Key Laboratory of Earth Surface Processes and Resource Ecology, Faculty of Geographical Science, Beijing Normal University, Beijing 100875, China

4. Department of Earth Sciences, Indiana University-Purdue University Indianapolis (IUPUI), Indianapolis 46202, United States

5. ARC Centre of Excellence for Climate Systems Science \& Climate Change Research Centre, University of New SouthWales, Sydney, New SouthWales2052, Australia.

6. Water Research Centre, School of Civil and Environmental Engineering, University of New SouthWales, Sydney, New SouthWales 2052, Australia.

\section{Corresponding author:}

Dr. Shuai Wang

Address:

State Key Laboratory of Earth Surface Processes and Resource Ecology, Faculty of

Geographical Science, Beijing Normal University No. 19, XinJieKouWai St., HaiDian

District, Beijing 100875, China

Tel (Fax): +86-10-62923557

E-mail: shuaiwang@bnu.edu.cn

Running Title:

African drylands ecosystem changes

This is the author's manuscript of the article published in final edited form as:

Wei, F., Wang, S., Fu, B., Wang, L., Liu, Y. Y., \& Li, Y. (2019). African dryland ecosystem changes controlled by soil water.

Land Degradation \& Development, 30(13), 1564-1573. https://doi.org/10.1002/ldr.3342 


\begin{abstract}
Monitoring long-term vegetation dynamics in African drylands is of great importance for both ecosystem degradation studies and carbon-cycle modelling. Here, we exploited the complementary use of optical and passive microwave satellite data - Normalized Difference Vegetation Index (NDVI) and Vegetation Optical Depth (VOD) - to provide new insights of ecosystem changes in African drylands. During 1993-2012, 54\% of African drylands experienced a significant increase of VOD, mainly located in southern Africa and west and central Africa, with an average rate of increase of $(1.2 \pm 2.7) \times 10^{-}$ ${ }^{3}$. However, a significant decreasing NDVI was observed over $43 \%$ of the African drylands, in particular in western Niger and eastern Africa, with an average browning rate of $(-0.13 \pm 1.5) \times 10^{-3}$. The contrasting vegetation trends (increasing VOD and decreasing NDVI) were largely caused by an increase in the relative proportion of the woody component of the vegetation, as a result of the prevailing woody encroachment in African drylands during the study period. Soil water emerges as the dominant driver of ecosystem changes in African drylands, in particular in arid and semi-arid areas. This is evidenced by a strong spatio-temporal correlation between soil water and vegetation, where soil water changes explain about $48 \%$ of vegetation variations. This study emphasizes the potential of utilizing multiple satellite products with different strengths in monitoring different characteristics of ecosystems to evaluate ecosystem changes and reveal the underlying mechanisms of the observed changes.
\end{abstract}

Key words: African drylands, soil water, vegetation optical depth, ecosystem changes, woody encroachment. 


\section{Introduction}

In sub-Saharan Africa, drylands make up more than $60 \%$ of the land and are home to about 425 million people (Cervigni \& Morris, 2016). The vegetation in these dryland areas provides vital products and services for local livelihoods (Adeel, Safriel, Niemeijer, \& White, 2005; Ryan et al., 2016). However, African dryland ecosystems are facing increased threats from climate change and human activities (Busby, Smith, \& Krishnan, 2014). Enhanced warming and a rapid human population growth will exacerbate the risk of land degradation and desertification in the near future (Huang, Yu, Guan, Wang, \& Guo, 2016; Wang et al., 2012). Monitoring long-term vegetation dynamics in drylands is of great importance for carbon-cycle modelling, projecting future ecosystem dynamics and implementing adaptation strategies to climate change (Ahlstrom et al., 2015; Liu et al., 2015).

Over the past few decades, an increase in woody plants, characterized by woody thickening and encroachment, has been widely reported in African drylands (Mitchard \& Flintrop, 2013; Sankaran et al., 2005; Tian, Brandt, Liu, Rasmussen, \& Fensholt, 2017; Wigley, Bond, \& Hoffman, 2010; Zhang et al., 2019). The studies focusing on woody vegetation trends in African drylands tend to use dry-season normalized difference vegetation index (NDVI) (Brandt et al., 2016; Horion, Fensholt, Tagesson, \& Ehammer, 2014; Mitchard \& Flintrop, 2013), which is derived from the near-infrared and red spectral reflections, and provides a measure of chlorophyll abundance in the canopy layer. Vegetation optical depth (VOD) derived from microwave domain is complementary to NDVI. Microwave signals can penetrate vegetation canopy and sense water content in both the leafy and woody vegetation components, and provide a measurement of aboveground biomass (Brandt et al., 2018; Liu, de Jeu, McCabe, Evans, \& van Dijk, 2011). These differences mean that NDVI is more sensitive to changes in herbaceous vegetation while VOD is more sensitive to changes in the woody component of the vegetation (Andela, Liu, van Dijk, de Jeu, \& McVicar, 2013).

Earlier analysis indicates that, due to their different characteristics, VOD and NDVI do not necessarily respond to environmental changes in an identical manner (Andela et 
al., 2013). Considering NDVI and VOD records together can, therefore, provide a more complementary and robust characterization of vegetation dynamics, especially for ecosystems consisting of a mixture of herbaceous and woody vegetation. Some potential insights from the combined interpretation of NDVI and VOD trends have already been reported. For example, Liu et al (2011) briefly compared NDVI and VOD patterns, and quantified spatiotemporal changes in VOD and the underlying drivers at a global scale (Liu, van Dijk, McCabe, Evans, \& de Jeu, 2013). Tian et al (2017) used VOD and NDVI data sets to separate leafy and woody components, to obtain a more accurate assessment of woody vegetation changes in global tropical drylands. However, these global scale studies did not focus specifically on vegetation dynamics in African drylands where trees and grasses co-exist for more than 60 million of years (Wang, D'Odorico, Ries, \& Macko, 2010).

Many factors drive ecosystem changes in African drylands. These include climate change, $\mathrm{CO}_{2}$ fertilization, fire regime, grazing and agriculture (Andela et al., 2013; Higgins \& Scheiter, 2012; Liu, van Dijk, McCabe, Evans, \& de Jeu, 2013; Muller, Overbeck, Pfadenhauer, \& Pillar, 2007; Wigley et al., 2010; Yu \& D'Odorico, 2014), but it is generally believed that vegetation changes in these areas are mainly controlled by water availability (Andela et al., 2013; Brandt, Rasmussen, et al., 2017; Liu, van Dijk, McCabe, Evans, \& de Jeu, 2013; Wang, D'Odorico, O'Halloran, Caylor, \& Macko, 2010). However, the relationship between vegetation and soil water has been found to be stronger than that between vegetation and rainfall, probably due to precipitation redistribution and its lag effects on vegetation growth (Ibrahim, Balzter, Kaduk, \& Tucker, 2015; Ji \& Peters, 2005; Wei et al., 2018). Soil water, which is directly available to vegetation, should be a better indicator for vegetation dynamics than precipitation. However, previous studies have often neglected or given little consideration to soil water (Andela et al., 2013; Brandt, Tappan, et al., 2017; Liu, van Dijk, McCabe, Evans, \& de Jeu, 2013).

The objective of this study is to investigate ecosystem changes in African drylands and explore the mechanisms driving them. Using optical-based NDVI and microwavebased VOD data from 1992 to 2013, we characterize the spatiotemporal changes of 
NDVI and VOD trends over African drylands based on a linear regression algorithm, and analyze the relationship between NDVI and VOD trends for different land cover types and climate zones. We examine how vegetation variations are spatiotemporally interrelated with changes in soil water, and finally, we quantify the relative weights of the underlying factors controlling ecosystem changes in African drylands.

\section{Material and Methods}

\subsection{Domain}

This study focuses on the dryland areas of continental Africa south of $20^{\circ} \mathrm{N}$ (i.e. excluding the Sahara Desert and northern Africa) (Fig. S1). Drylands are defined, according to the United Nations Environment Program (UNEP) aridity map, as regions with an aridity index (i.e. the ratio of annual precipitation to annual potential evapotranspiration) below 0.65 (UNEP, 1997). The category includes hyperarid, arid, semi-arid, and dry sub-humid regions. All the analyses are performed at a spatial resolution of $0.25^{\circ}$ to match the original resolution of the VOD data set. Data were acquired from January 1993 through December 2012. Information on data availability can be found in the supplementary material.

\subsection{Data sets}

\subsubsection{Vegetation data}

We used the updated third generation NDVI data set from the Global Inventory Modeling and Mapping Studies (GIMMS NDVI3g.v1), which is available biweekly at a spatial resolution of $1 / 12^{\circ}$ for the entire duration of our study period. Multiple processing steps have been taken to minimize the errors arising from inter-sensor calibration, volcanic aerosols, orbital drift, and atmospheric conditions (Pinzon \& Tucker, 2014). GIMMS NDVI $3 \mathrm{~g}$ has better temporal consistency than other long-term NDVI datasets (Tian et al., 2015). In addition, GIMMS NDVI 3g.v1 is strongly recommended for future analysis in dryland regions rather than GIMMS NDVI 3g.v0 due to the extreme outliers (Burrell, Evans, \& Liu, 2018). In this study, to further reduce the effects of cloud and haze contaminations, monthly NDVI data were generated by the maximum value composite method. Pixels with annual mean NDVI $<0.1$ were 
considered to be non-vegetated and were masked (de Jong, Verbesselt, Zeileis, \& Schaepman, 2013).

Gridded monthly $0.25^{\circ}$ resolution VOD data for 1993-2012 were retrieved from a series of passive microwave satellite sensors (Liu, de Jeu, McCabe, Evans, \& van Dijk, 2011). The errors associated with sensor changes in the harmonized VOD data set are small, and the merged data set captures long-term changes in aboveground vegetation water content at a global scale without contamination from sensor artefacts (Liu, van Dijk, McCabe, Evans, \& de Jeu, 2013). When VOD values exceed 1.2, any further potential changes in the vegetation canopy cannot be captured (Owe, de Jeu, \& Walker, 2001), and so areas with VOD larger than 1.2 were masked out. We also masked lakes, rivers, and reservoirs since open water affects the microwave emissions (Liu, van Dijk, McCabe, Evans, \& de Jeu, 2013).

\subsubsection{Environmental data}

Monthly hydrometeorological data, obtained from the Global Land Data Assimilation System (GLDAS) were used. These data consisted of temperature, precipitation, solar radiation, and soil water (the average soil water content of the top $200-\mathrm{cm}$ layer) and were from the Noah Land Surface Model L4 that contains a series of land surface parameters simulated from the Noah 3.3 model (Horion et al., 2014). More details about GLDAS data sets are given by Rodell et al., 2004. The difference in human population density between 1990 and 2010 was based on the Gridded Population of the World dataset (GPWv4). Soil organic carbon and sand fraction were obtained from the Harmonized World Soil Database (HWSD v1.2) (Wieder, Boehnert, Bonan, \& Langseth, 2014). Mean annual burned fraction data for $1997-2012$ were obtained from the Global Fire Emissions Database (GFED4s) (Giglio, Randerson, \& van der Werf, 2013). Elevation data were obtained from Global Multi-Resolution Terrain Elevation Data 2010 (Danielson \& Gesch, 2011). We resampled the soil and elevation data to a $0.25^{\circ}$ spatial resolution using nearest neighbor interpolation.

\subsubsection{Land cover data}


Land cover data were derived from the MODIS MCD12C1 product using the 17-class International Geosphere-Biosphere Programme (IGBP) classification scheme. To reduce the impacts of classification error and land cover change, only stable pixels defined as those areas with no changes in the dominant land cover class during 20012012 - were considered (Forzieri, Alkama, Miralles, \& Cescatti, 2017). Six land cover classes were considered in this study: open shrublands (OSH), woody savannas (WSA), savannas (SAV), grasslands (GRA), crops (including crops/natural vegetation mosaics) (CRO), and barren or sparsely vegetated land (BSV) (Fig. S1 \& Table.S1).

\subsection{Methods}

\subsubsection{Linear regression}

Linear regression based on least-squares is widely used in trend detection for vegetation change and climate variations ( $\mathrm{Lu}$ et al., 2015). At the pixel level, the least-squares regression equation can be represented as follows:

$$
\mathrm{y}=\mathrm{a} \times \mathrm{t}+\mathrm{b}+\varepsilon
$$

where $y$ is the dependent variable (i.e., NDVI, VOD) in year $t ; a$ is the slope of the equation (the change rate of the linear trend); $b$ is the intercept of the equation; and $\varepsilon$ is the error. In our case, $t$ ranges from 1993 to $2012(t \in N)$, so the sample size for each pixel is 20. Change is statistically significant at the $p<0.05$ level.

\subsubsection{Spearman's rank correlation}

Spearman's rank correlation coefficient was calculated to quantify the relationship between two variables. The significance level of correlation $(p<0.05)$ is estimated using a two-tailed student's $t$-test. The null hypothesis is that the two variables used to calculate the correlation coefficient are independent (that is $R=0$ ) (Zhou et al., 2014).

\subsubsection{Singular value decomposition}

The singular value decomposition (SVD) technique provides a way to separate coupled modes of variability between two fields and to identify the relationship between them (Deng et al., 2016). SVD can produce a set of functions that represent the dominant modes of variation in spatiotemporal data sets, and the relative importance of each pattern in explaining the observed variation across space (Liu, van Dijk, McCabe, Evans, \& de Jeu, 2013). The spatial modes show the spatial structure of the major 
factors that can account for the temporal variations. The time series show how the amplitude of the corresponding spatial mode varies with time (Liu, van Dijk, McCabe, Evans, \& de Jeu, 2013; von Storch \& Zwiers, 2002).

\subsubsection{Relative importance calculation}

We used a bootstrapping technique based on the LMG (Lindeman, Merenda and Gold) method to estimate the relative contributions of controlling factors to the annual changes of VOD (Gromping, 2007). The controlling factors considered in this study are as follows: change in soil water; change in temperature; change in solar radiation; change in population density; change in burned area fraction; mean annual rainfall; soil organic carbon; soil sand fraction; elevation. The LMG method estimates the relative importance of each variable by decomposing the sum of squares into non-negative contributions shared by each variable. Before the modelling, each variable was normalized using the $\mathrm{Z}$ score for each year $(s)$ and each grid cell $(i, j): X_{z-s c o r e, s(i j)}=$

$\frac{X_{s(i j)}-\mu X_{1993-2012(i j)}}{\sigma X_{1993-2012(i j)}}$. All explanatory variables were tested for no multi-collinearity by Variance Inflation Factor values $(\mathrm{VIF}<5$, Table.S2). The model was run for the African drylands and its sub-regions, which include arid, semi-arid, and dry sub-humid regions (Table. S3 \&Fig. S6).

\section{Results}

\subsection{Changes in NDVI and VOD}

The spatial pattern of annual mean NDVI was similar to that of annual mean VOD, and both had a strong similarity to the aridity map (Fig. S1 \& S2). However, annual changes in VOD and NDVI were different during 1993-2012 (Fig. 1). For VOD, more than half of the African drylands (54\%) experienced a significant increase of VOD. This increase was particularly strong in southern Africa and west and central Africa (i.e., Senegal, Mali, Niger, Chad and Sudan), with an average increase rate of $(1.2 \pm 2.7) \times 10^{-3} \mathrm{yr}^{-1}$. A decrease of VOD was located in the sub-humid zones of Nigeria, Ghana, and eastern Africa (except for northwestern Kenya and southwestern Tanzania)(Fig. 1a). For NDVI, however, browning was concentrated in western Niger and eastern Africa (43\% with a significant decrease), with an average decrease rate of $(-0.13 \pm 1.5) \times 10^{-3} \mathrm{yr}^{-1}$. Positive 
NDVI trends were found in the sub-humid zones of west and central Africa (i.e., Senegal, Ghana, Benin and the south of Sudan) and Namibia in southern Africa (Fig. 1b). Overall, during the period of 1993-2012, there was a large interannual fluctuation for NDVI, but a significant increasing trend (+0.024) for VOD $(p<0.05)$ (Fig. 1c).

The spatial correspondence of changes in NDVI and VOD is shown in Fig. 1d, which can provide new insights into the relative performance of herbaceous and woody vegetation components in drylands. Most of the African drylands showed consistent NDVI and VOD trends (35.3\% of the area had both trends increasing; $21.4 \%$ had both trends decreasing). For areas of both increased NDVI and VOD, particularly in the OS, SVA and WSA areas of west and central Africa and southern Africa, large clusters of pixels show higher trends in VOD than NDVI (Fig. 1, Table. 1). Areas with both decreased NDVI and VOD trends were concentrated in a large area of eastern Africa (i.e., Ethiopia, Kenya, Tanzania and Somalia). Areas with increased VOD and decreased NDVI occupied $32 \%$ of the study area, were mainly located in the GRA and BSV of west and central Africa and southern Africa (Fig. 1d, Table. 1), signifying an increase in the relative fraction of non-photosynthetic components (Andela et al., 2013). The combination of decreased VOD and increased NDVI was sparsely distributed in Nigeria and related to large scale forest to farmland conversions (Audu, 2013).

Due to the individual characteristics of the VOD and NDVI products, different responses to changes in land cover are to be expected. In particular, the GRA and BSV showed a predominance of areas with positive trends in VOD and negative trends in NDVI (Fig. 2, Table .1). For regions primarily consisting of savanna and shrubland, a mixture of herbaceous and woody plants, the VOD trends were much greater than the NDVI trends (Fig. 2). The more soil water, the greater the vegetation production, although the increase with increasing humidity is faster for VOD than for NDVI (Fig. 3a). The NDVI trends increased with increasing humidity, with negative NDVI trends over arid regions and small positive NDVI trends in more humid areas. In contrast, the VOD trends were positive in all climate zones. The VOD increases were strongest for semi-arid regions (Fig. 3b), which is consistent with widespread observations of woody encroachment over semi-arid areas (Andela et al., 2013). An increase in soil water was 
also observed in arid and semi-arid zones, with relatively larger changes in the drier environments (Fig. 3b).

\subsection{Soil water driving ecosystem changes in African drylands}

The spatial pattern of annual mean soil water is markedly different from that of the soil water trends (Fig. 4a, b). Dry areas became wetter during 1993-2012, while wet areas became drier (Fig. 4a, b \& Fig. S3a, b). The strongest drying trends were seen in eastern Africa (i.e., Kenya, Tanzania, Sudan, and Ethiopia) (Fig. 4b). The spatial pattern of VOD trends roughly matched that of soil water trends (Fig. 1a, 4b), with the exceptions of Somalia and the sub-humid zones of west and central Africa. Additionally, we found that VOD had a significantly positive correlation $(p<0.05)$ with soil water in most (about $60 \%$ ) of the African drylands, especially in the dry regions. The positive correlation between NDVI and soil water was slightly weaker than that between VOD and soil water (Fig. 4c, d). Moreover, the positive relationship between soil water and vegetation growth is stronger than that between precipitation and vegetation growth (Fig. 4c, d \& Fig. S3c, d), in line with previous studies (Ibrahim et al., 2015; Ji \& Peters, 2005; Wei et al., 2018).

The SVD method was applied to investigate how interannual variations of the vegetation are linked to changes in soil water. Figure 5 shows the spatial structures and time series of the first paired modes of VOD and soil water for the period of 1993-2012 in three sub regions. The first SVD mode explained $84.8 \%, 82.7 \%$ and $89.8 \%$ of the total squared covariance between the two fields in west and central Africa, eastern Africa, and southern Africa, respectively; with the correlations between the spatial modes being $0.83,0.90$ and 0.91 , respectively. These values imply a strong linkage between VOD and soil water in these regions. Specifically, the spatial mode of the VOD field is characterized by positive anomalies, and the corresponding soil water anomaly pattern is also characterized by positive values over most of the domain. The increase in the time series for west and central Africa and southern Africa indicates that the increased soil water contributed to vegetation growth there (Fig. 5c, i), while, in eastern Africa, the decrease in the time series points to decreased soil water leading to a reduction in vegetation (Fig 5f). The large explained squared covariance, and strong 
temporal correlation between VOD and soil water, suggest a strong covariability between these two fields throughout the study period. However, the spatiotemporal correlations between NDVI and soil water are weaker than those between VOD and soil water, especially in west and central Africa. The role played by soil water in the NDVI changes in these areas requires further study (Fig. S4) (Dardel et al., 2014). The SVD analysis adds further weight to the idea that soil water has a stronger spatiotemporal correlation with vegetation than precipitation due to the lag effects of precipitation on plant growth (Fig. 5 \& Fig. S5).

A relative importance algorithm was applied to attribute the annual changes in VOD during 1993 - 2012 to its drivers (see method). We found that changes in soil water were the leading factor controlling changes in VOD with relative weights of $48.4 \%$ for all drylands, $52.0 \%$ in arid, $41.0 \%$ in semi-arid and $37.9 \%$ in dry sub-humid regions (Fig. 6). It is worth noting that the contribution of factors related to energy (temperature and solar radiation) and disturbance (fire, human population density) to VOD changes reached $37 \%$ in dry sub-humid areas. Static conditions included mean annual rainfall, soil organic carbon, sand fraction, and elevation, which together contributed $25 \%$ to $53 \%$ to VOD changes (Fig. 6). Change in rainfall was excluded from the analysis due to its close relationship with changes in soil water, and soil water has a larger explaining power for VOD than precipitation. Table S2 lists all explanatory variables without multicollinearity by variance inflation factor values $(\mathrm{VIF}<5)$. The contribution of each explanatory factor to changes in VOD is shown in Figure. S6.

\section{Discussion}

The relationship between the NDVI and VOD trends can provide new insights into the relative performance of herbaceous and woody vegetation components in drylands. During 1993-2012, we found that NDVI and VOD had opposing trends over $32 \%$ of the African drylands: VOD increased at an average rate of $(1.2 \pm 2.7) \times 10^{-3}$ and NDVI had a small overall decreasing rate of $(-0.13 \pm 1.5) \times 10^{-3}$ (Fig. 1). A large proportion of each land cover type (ranging from nearly $23 \%$ to $54 \%$ ) showed an increase in VOD and a decrease in NDVI (Table 1). We attribute these contrasting trends to the fact that 
VOD and NDVI represent different characteristics of the vegetation, and infer an increase in the relative proportion of the woody component of the vegetation in African drylands (Andela et al., 2013; R. Fensholt et al., 2015). The results add further weight to the idea, widely reported over the last decades (Mitchard \& Flintrop, 2013; Skowno et al., 2017; Wigley et al., 2010), that woody encroachment prevailed in African drylands during 1993-2012. Moreover, hot spot areas of increased VOD coincide with areas where woody vegetation increased has been reported (Tian, Brandt, Liu, Rasmussen, \& Fensholt, 2017; Zhang et al., 2019). Contrary to the widespread greening in the African Sahel interpreted as a recovery from the great Sahelian droughts (Anyamba \& Tucker, 2005; Herrmann, Anyamba, \& Tucker, 2005), our study observed a recently decreasing NDVI in the Sahel with the most pronounced decrease in eastern Sudan and western Niger. This decrease in NDVI is consistent with previous studies documenting the Sahelian re-greening which has occurred since the 1980s, which found a constant decline in NDVI over Niger starting in the mid-1990s that could not be explained by rainfall (Dardel et al., 2014; R. Fensholt \& Rasmussen, 2011).

Our study shows that $54 \%$ of the African drylands experienced a significant increase in VOD during 1993-2012, and this was particularly strong in arid and semi-arid areas (Fig. 1a, 3b). At the same time, an increase in soil water was observed in $66.7 \%$ of the above areas (Fig. S7). In contrast, a negative VOD trend was observed in eastern Africa along with a drying soil-water trend (Fig. 1a, 4b). Generally, the spatiotemporal evolution of trends in VOD roughly matched those in soil water (about 62.7\%) except for some areas in west and central Africa and Somalia (Fig. S7). In Somalia, it is conceivable that the increased soil water along with the negative trends in both NDVI and VOD might be interpreted as human-induced land degradation, caused by a combination of factors such as overgrazing, deforestation, poor agronomic practice and civil strife and conflict (Omuto, Balint, \& Alim, 2014). A significant positive correlation $(p<0.05)$ between VOD and soil water was found in $60 \%$ of the African drylands. The high percentage of captured covariance between VOD and soil water, and the clear consistent trends found in the time series, suggest that soil water was the dominant factor governing VOD changes in African drylands (Fig. 5). Overall, in accordance with $12 / 26$ 
previous studies documenting the effects of water availability on drylands ecosystem changes (Brandt et al., 2015; Brandt, Tappan, et al., 2017; Huber, Fensholt, \& Rasmussen, 2011; R. Fensholt et al., 2012; Ibrahim et al., 2015; Wei et al., 2018; Zhang et al., 2019), our study showed that ecosystem changes are controlled by soil water in African drylands.

At the same time, we found that pixels with negative trends in NDVI and positive trends in soil water cover $33.4 \%$ of the African drylands, mainly in Somalia, southern Africa and the north of about $14^{\circ} \mathrm{N}$, while the same regions (with the exception of Somalia) showed an increase in VOD (Fig. S7). This result is consistent with early observations by Andela et al (2013), which suggested that woody plants benefit more from increased soil water than herbaceous vegetation (Zhang et al., 2019). The contribution of soil water to vegetation changes decreased with increasing humidity (Fig. S6). Disturbance processes such as wildfires and human activities also affected the ecosystem structures and dynamic trends, in particular in dry sub-humid areas where energy availability plays an important role in vegetation changes (Fig. 6 \& Fig. S6). These results are in line with a pervious study which showed that a decline in burned area, along with warmer and wetter climates, drove woody plant increase over Africa (Venter, Cramer, \& Hawkins, 2018). Increased atmospheric $\mathrm{CO}_{2}$ concentration facilitates vegetation productivity, particularly the growth of woody plants, which may also enhance the risk of woody encroachment (Venter et al., 2018). Future studies should integrate satellite observations, field monitoring, and process-based ecosystem models to increase confidence in the ecosystem changes presented here and the proposed driving mechanisms, and therefore help to project future ecosystem evolution and implement effective ecosystem management.

\section{Conclusion}

Considering both NDVI and VOD helps to better characterize ecosystem changes in the African drylands. The decreased NDVI and increased VOD provides evidence of widespread woody plant increase in these areas. Soil water emerges as the dominant driver of ecosystem changes in African drylands, in particular in arid and semi-arid 
areas. Our results, derived from large scale satellite observations, help to explain ecosystem changes in African drylands and the underlying driving mechanisms, but techniques such as these still require verification from more detailed ground-based fieldwork in the future.

\section{Acknowledgement}

This work was funded by the National Key Research and Development Program of China (2017YFA0604701), National Natural Science Foundation of China (41761144064) and Chinese Academy of Sciences (QYZDY-SSW-DQC025). We also acknowledge the contributions of the anonymous referees and the editors, whose suggestions significantly improved this manuscript.

\section{References}

Adeel, Z., Safriel, U., Niemeijer, D., \& White, R. (2005). Ecosystems and human well-being: desertification synthesis. World Resources Institute (WRI)

Ahlstrom, A., Raupach, M. R., Schurgers, G., Smith, B., Arneth, A., Jung, M., . . . Zeng, N. (2015). The dominant role of semi-arid ecosystems in the trend and variability of the land CO2 sink. Science, 348(6237), 895-899. doi:10.1126/science.aaa1668

Andela, N., Liu, Y. Y., van Dijk, A. I. J. M., de Jeu, R. A. M., \& McVicar, T. R. (2013). Global changes in dryland vegetation dynamics (1988-2008) assessed by satellite remote sensing: comparing a new passive microwave vegetation density record with reflective greenness data. Biogeosciences, 10(10), 6657-6676. doi:10.5194/bg-10-6657-2013

Anyamba, A., \& Tucker, C. J. (2005). Analysis of Sahelian vegetation dynamics using NOAA-AVHRR NDVI data from 1981-2003. Journal of arid environments, 63(3), 596-614. doi:10.1016/j.jaridenv.2005.03.007

Audu, E. (2013). Fuel wood consumption and desertification in Nigeria. International Journal of Science and Technology, 3(1), 1-5.

Brandt, M., Hiernaux, P., Rasmussen, K., Mbow, C., Kergoat, L., Tagesson, T., . . Fensholt, R. (2016). Assessing woody vegetation trends in Sahelian drylands using MODIS based seasonal metrics. Remote Sensing of Environment, 183, 215-225. doi:10.1016/j.rse.2016.05.027

Brandt, M., Mbow, C., Diouf, A. A., Verger, A., Samimi, C., \& Fensholt, R. (2015). Ground- and satellitebased evidence of the biophysical mechanisms behind the greening Sahel. Global Change Biology, 21(4), 1610-1620. doi:10.1111/gcb.12807

Brandt, M., Rasmussen, K., Penuelas, J., Tian, F., Schurgers, G., Verger, A., . . Fensholt, R. (2017). Human population growth offsets climate-driven increase in woody vegetation in sub-Saharan Africa. Nat Ecol Evol, 1(4), 81. doi:10.1038/s41559-017-0081

Brandt, M., Tappan, G., Diouf, A. A., Beye, G., Mbow, C., \& Fensholt, R. (2017). Woody Vegetation Die off and Regeneration in Response to Rainfall Variability in the West African Sahel. Remote Sensing, 9(1). doi:ARTN 3910.3390/rs9010039

Brandt, M., Wigneron, J. P., Chave, J., Tagesson, T., Penuelas, J., Ciais, P., . . Fensholt, R. (2018). Satellite 
passive microwaves reveal recent climate-induced carbon losses in African drylands. Nat Ecol Evol, 2(5), 827-835. doi:10.1038/s41559-018-0530-6

Burrell, A. L., Evans, J. P., \& Liu, Y. (2018). The impact of dataset selection on land degradation assessment. ISPRS journal of photogrammetry and remote sensing, 146, 22-37. doi:10.1016/j.isprsjprs.2018.08.017

Busby, J. W., Smith, T. G., \& Krishnan, N. (2014). Climate security vulnerability in Africa mapping 3.0. Political Geography, 43, 51-67.

Cervigni, R., \& Morris, M. (2016). Confronting Drought in Africa's Drylands: Opportunities for Enhancing Resilience: The World Bank.

Danielson, J. J., \& Gesch, D. B. (2011). Global multi-resolution terrain elevation data 2010 (GMTED2010) (2331-1258). US Geological Survey.

Dardel, C., Kergoat, L., Hiernaux, P., Mougin, E., Grippa, M., \& Tucker, C. J. (2014). Re-greening Sahel: 30 years of remote sensing data and field observations (Mali, Niger). Remote Sensing of Environment, 140, 350-364. doi:10.1016/j.rse.2013.09.011

de Jong, R., Verbesselt, J., Zeileis, A., \& Schaepman, M. (2013). Shifts in Global Vegetation Activity Trends. Remote Sensing, 5(3), 1117-1133. doi:10.3390/rs5031117

Deng, J., Sun, P., Zhao, F., Han, X., Yang, G., \& Feng, Y. (2016). Analysis of the ecological conservation behavior of farmers in payment for ecosystem service programs in eco-environmentally fragile areas using social psychology models. Sci Total Environ, 550, 382-390. doi:10.1016/j.scitotenv.2016.01.152

Fensholt, R., Horion, S., Tagesson, T., Ehammer, A., Ivits, E., \& Rasmussen, K. (2015). Global - scale mapping of changes in ecosystem functioning from earth observation - based trends in total and recurrent vegetation. Global Ecology and Biogeography, 24(9), 1003-1017. doi:10.1111/geb.12338

Fensholt, R., Langanke, T., Rasmussen, K., Reenberg, A., Prince, S. D., Tucker, C., . . Wessels, K. (2012). Greenness in semi-arid areas across the globe 1981-2007 - an Earth Observing Satellite based analysis of trends and drivers. Remote Sensing of Environment, 121, 144-158. doi:10.1016/j.rse.2012.01.017

Fensholt, R., \& Rasmussen, K. (2011). Analysis of trends in the Sahelian 'rain-use efficiency' using GIMMS NDVI, RFE and GPCP rainfall data. Remote Sensing of Environment, 115(2), 438-451. doi:10.1016/j.rse.2010.09.014

Forzieri, G., Alkama, R., Miralles, D. G., \& Cescatti, A. (2017). Satellites reveal contrasting responses of regional climate to the widespread greening of Earth. Science, 356(6343), 1140-1144. doi:10.1126/science.aal1727

Giglio, L., Randerson, J. T., \& van der Werf, G. R. (2013). Analysis of daily, monthly, and annual burned area using the fourth - generation global fire emissions database (GFED4). Journal of Geophysical Research: Biogeosciences, 118(1), 317-328.

Gromping, U. (2007). Estimators of relative importance in linear regression based on variance decomposition. American Statistician, 61(2), 139-147. doi:10.1198/000313007×188252

Herrmann, S. M., Anyamba, A., \& Tucker, C. J. (2005). Recent trends in vegetation dynamics in the African Sahel and their relationship to climate. Global Environmental Change-Human and Policy Dimensions, 15(4), 394-404. doi:10.1016/j.gloenvcha.2005.08.004

Higgins, S. I., \& Scheiter, S. (2012). Atmospheric CO 2 forces abrupt vegetation shifts locally, but not globally. Nature, 488(7410), 209. doi: 10.1038/nature11238 
Horion, S., Fensholt, R., Tagesson, T., \& Ehammer, A. (2014). Using earth observation-based dry season NDVI trends for assessment of changes in tree cover in the Sahel. International Journal of Remote Sensing, 35(7), 2493-2515. doi:10.1080/01431161.2014.883104

Huang, J. P., Yu, H. P., Guan, X. D., Wang, G. Y., \& Guo, R. X. (2016). Accelerated dryland expansion 452 under climate change. Nature Climate Change, 6(2), 166-+. doi:10.1038/Nclimate2837

Huber, S., Fensholt, R., \& Rasmussen, K. (2011). Water availability as the driver of vegetation dynamics in the African Sahel from 1982 to 2007. Global and Planetary Change, 76(3-4), 186-195. doi:10.1016/j.gloplacha.2011.01.006

Ibrahim, Y. Z., Balzter, H., Kaduk, J., \& Tucker, C. J. (2015). Land Degradation Assessment Using Residual Trend Analysis of GIMMS NDVI3g, Soil Moisture and Rainfall in Sub-Saharan West Africa from 1982 to 2012. Remote Sensing, 7(5), 5471-5494. doi:10.3390/rs70505471

Ji, L., \& Peters, A. J. (2005). Lag and seasonality considerations in evaluating AVHRR NDVI response to precipitation. Photogrammetric Engineering \& Remote Sensing, 71(9), 1053-1061. doi: 10.14358/PERS.71.9.1053

Liu, Y. Y., de Jeu, R. A. M., McCabe, M. F., Evans, J. P., \& van Dijk, A. I. J. M. (2011). Global long-term passive microwave satellite-based retrievals of vegetation optical depth. Geophysical Research Letters, 38(18), n/a-n/a. doi:10.1029/2011gl048684

Liu, Y. Y., van Dijk, A. I. J. M., de Jeu, R. A. M., Canadell, J. G., McCabe, M. F., Evans, J. P., \& Wang, G. J. (2015). Recent reversal in loss of global terrestrial biomass. Nature Climate Change, 5(5), 470474. doi:10.1038/Nclimate2581

Liu, Y. Y., van Dijk, A. I. J. M., McCabe, M. F., Evans, J. P., \& de Jeu, R. A. M. (2013). Global vegetation biomass change (1988-2008) and attribution to environmental and human drivers. Global Ecology and Biogeography, 22(6), 692-705. doi:10.1111/geb.12024

Lu, Y. H., Zhang, L. W., Feng, X. M., Zeng, Y., Fu, B. J., Yao, X. L., . . W Wu, B. F. (2015). Recent ecological transitions in China: greening, browning, and influential factors. Scientific Reports, 5. doi:ARTN 873210.1038/srep08732

Mitchard, E. T. A., \& Flintrop, C. M. (2013). Woody encroachment and forest degradation in sub-Saharan Africa's woodlands and savannas 1982-2006. Philosophical Transactions of the Royal Society BBiological Sciences, 368(1625). doi:ARTN 2012040610.1098/rstb.2012.0406

Muller, S. C., Overbeck, G. E., Pfadenhauer, J., \& Pillar, V. D. (2007). Plant functional types of woody species related to fire disturbance in forest-grassland ecotones. Plant Ecology, 189(1), 1-14. doi:10.1007/s11258-006-9162-z

Omuto, C. T., Balint, Z., \& Alim, M. S. (2014). A Framework for National Assessment of Land Degradation in the Drylands: A Case Study of Somalia. Land Degradation \& Development, 25(2), 105-119. doi:10.1002/ldr.1151

Owe, M., de Jeu, R., \& Walker, J. (2001). A methodology for surface soil moisture and vegetation optical depth retrieval using the microwave polarization difference index. leee Transactions on Geoscience and Remote Sensing, 39(8), 1643-1654. doi:Doi 10.1109/36.942542

Pinzon, J. E., \& Tucker, C. J. (2014). A Non-Stationary 1981-2012 AVHRR NDVI3g Time Series. Remote Sensing, 6(8), 6929-6960. doi:10.3390/rs6086929

Rodell, M., P.R. Houser, U. Jambor, J. Gottschalck, K. Mitchell, C. Meng, K. Arsenault, B. Cosgrove, J. Radakovich, M. Bosilovich, J.K. Entin, J.P. Walker, D. Lohmann, and D. Toll. (2004). The global land data assimilation system. Bulletin of the American Meteorological Society, 85(3), 381-394. doi: 10.1175/BAMS-85-3-381 
Ryan, C. M., Pritchard, R., McNicol, L., Owen, M., Fisher, J. A., \& Lehmann, C. (2016). Ecosystem services from southern African woodlands and their future under global change. Philosophical Transactions of the Royal Society B-Biological Sciences, 371(1703). doi:ARTN 2015031210.1098/rstb.2015.0312

Sankaran, M., Hanan, N. P., Scholes, R. J., Ratnam, J., Augustine, D. J., Cade, B. S., . . Zambatis, N. (2005). Determinants of woody cover in African savannas. Nature, 438(7069), 846-849. doi:10.1038/nature04070

Skowno, A. L., Thompson, M. W., Hiestermann, J., Ripley, B., West, A. G., \& Bond, W. J. (2017). Woodland expansion in South African grassy biomes based on satellite observations (1990-2013): general patterns and potential drivers. Global Change Biology, 23(6), 2358-2369. doi:10.1111/gcb.13529

Tian, F., Brandt, M., Liu, Y. Y., Rasmussen, K., \& Fensholt, R. (2017). Mapping gains and losses in woody vegetation across global tropical drylands. Global Change Biology, 23(4), 1748-1760. doi:10.1111/gcb.13464

Tian, F., Fensholt, R., Verbesselt, J., Grogan, K., Horion, S., \& Wang, Y. J. (2015). Evaluating temporal consistency of long-term global NDVI datasets for trend analysis. Remote Sensing of Environment, 163, 326-340. doi:10.1016/j.rse.2015.03.031

UNEP. (1997). World atlas of desertification(2nd Edn). Arnold, London 1997, 182 pp.

Venter, Z. S., Cramer, M. D., \& Hawkins, H. J. (2018). Drivers of woody plant encroachment over Africa. Nature Communications, 9. doi:ARTN 227210.1038/s41467-018-04616-8

von Storch, H., \& Zwiers, F. W. (2002). Statistical analysis in climate research. In: Citeseer.

Wang, L., d'Odorico, P., Evans, J., Eldridge, D., McCabe, M., Caylor, K., \& King, E. (2012). Dryland ecohydrology and climate change: critical issues and technical advances. Hydrology and Earth System Sciences, 16(8), 2585-2603. doi:10.5194/hess-16-2585-2012

Wang, L., D'Odorico, P., Ries, L., \& Macko, S. A. (2010). Patterns and implications of plant-soil $\delta 13$ C and $\delta 15 \mathrm{~N}$ values in African savanna ecosystems. Quaternary Research, 73(1), 77-83. doi:10.1016/j.yqres.2008.11.004

Wang, L. X., D'Odorico, P., O'Halloran, L. R., Caylor, K., \& Macko, S. (2010). Combined effects of soil moisture and nitrogen availability variations on grass productivity in African savannas. Plant and Soil, 328(1-2), 95-108. doi:10.1007/s11104-009-0085-z

Wei, F., Wang, S., Fu, B., Pan, N., Feng, X., Zhao, W., \& Wang, C. (2018). Vegetation dynamic trends and the main drivers detected using the ensemble empirical mode decomposition method in East Africa. Land Degradation \& Development, 29(8), 2542-2553. doi:10.1002/Idr.3017

Wieder, W., Boehnert, J., Bonan, G., \& Langseth, M. (2014). Re-gridded Harmonized World Soil Database v1. 2, Data set, OakRidge National Laboratory Distributed Active Archive Center, Oak Ridge, Tennessee, USA. In.

Wigley, B. J., Bond, W. J., \& Hoffman, M. T. (2010). Thicket expansion in a South African savanna under divergent land use: local vs. global drivers? Global Change Biology, 16(3), 964-976. doi:10.1111/j.1365-2486.2009.02030.x

Yu, K., \& D'Odorico, P. (2014). An ecohydrological framework for grass displacement by woody plants in savannas. Journal of Geophysical Research: Biogeosciences, 119(3), 192-206. doi: 10.1002/2013JG002577

Zhang, W. M., Brandt, M., Penuelas, J., Guichard, F., Tong, X. Y., Tian, F., \& Fensholt, R. (2019). Ecosystem structural changes controlled by altered rainfall climatology in tropical savannas. Nature 
Communications, 10. doi:ARTN 67110.1038/s41467-019-08602-6

Zhou, L. M., Tian, Y. H., Myneni, R. B., Ciais, P., Saatchi, S., Liu, Y. Y., . . Hwang, T. H. (2014). Widespread decline of Congo rainforest greenness in the past decade. Nature, 509(7498), 86-+. doi:10.1038/nature13265 


\section{Table Legends}

Table. 1 The percentage of areas with various combination of increasing and decreasing NDVI and VOD trends in each land cover type.

\section{Table}

Table. 1 The percentage of areas with various combination of increasing and decreasing NDVI and VOD trends in each land cover type.

\begin{tabular}{ccccc}
\hline Land cover & NDVI $\uparrow$ VOD $\uparrow$ & NDVI $\uparrow$ VOD $\downarrow$ & NDVI $\downarrow$ VOD $\downarrow$ & NDVI $\downarrow$ VOD $\uparrow$ \\
\hline OS & 43.62 & 4.51 & 23.60 & 28.27 \\
SAV & 41.89 & 12.26 & 15.79 & 30.05 \\
GRA & 28.73 & 6.56 & 23.90 & 40.80 \\
WSA & 41.66 & 15.98 & 17.29 & 25.07 \\
BSV & 19.36 & 4.33 & 22.27 & 54.03 \\
CRO & 29.73 & 23.55 & 24.07 & 22.65 \\
\hline
\end{tabular}




\section{Figure Legends}

Fig. 1 Spatio-temporal changes of the observed NDVI and VOD and their co-relationship during 1993-2012: (a) VOD; (b) NDVI; (c) changes of annual mean NDVI/VOD for all vegetated African drylands; (d) co-relationship of NDVI and VOD trends divided into four classes $(p<0.05)$.

Fig. 2 Spatial agreement of areas with changes in VOD and areas with changes in NDVI for different land cover types. (a) Open shrublands (OS); (b) Savannas (SAV); (c) Grasslands (GRA); (d) Woody savannas (WSA); (e) Barren and sparsely vegetated (BSV); (f) Cropland (CRO).

Fig. 3 Box plots of the distribution of annual mean NDVI, VOD, and soil water classified by aridity classes (a). Box plots of the distribution of observed linear trends for NDVI, VOD, and soil water classified by aridity classes (b). The maximum and minimum extents of the colored boxes indicate the 25th and 75th percentiles and the whiskers represent the 5th and 95th percentiles.

Fig. 4 Spatial patterns of the annual mean value of soil water (a) and (b) the trends during 19932012. Correlations (c) between soil water and NDVI and (d) between soil water and VOD.

Fig. 5 Spatial patterns (left column) and time series (right column) of the first singular value decomposition mode between VOD and soil water for the period of 1993-2012 in the three sub regions indicated by the dashed black boxes in Fig. S1: west and central Africa (a-c), eastern Africa (d-f) and southern Africa (g-i).

Fig. 6 Relative importance of controlling factors explaining changes in VOD $(1993$ - 2012) from the LMG method based on a least square regression model. Explanatory variables are: change in soil water $\left(\mathrm{mm} / \mathrm{mm} \mathrm{yr}^{-1}\right)$; change in temperature $\left(\mathrm{K} \mathrm{yr}^{-1}\right)$ and solar radiation $\left(\mathrm{W} \mathrm{m}^{-2} \mathrm{yr}^{-1}\right)$; disturbance includes change in population (person $\left.\mathrm{km}^{-2}\right)$ and burned area fraction $\left(\% \mathrm{yr}^{-2}\right)$; Static variables include: mean annual rainfall ( $\left.\mathrm{mm} \mathrm{yr}^{-1}\right)$; soil organic carbon (SOC); Sand fraction (\%); and elevation (m). 

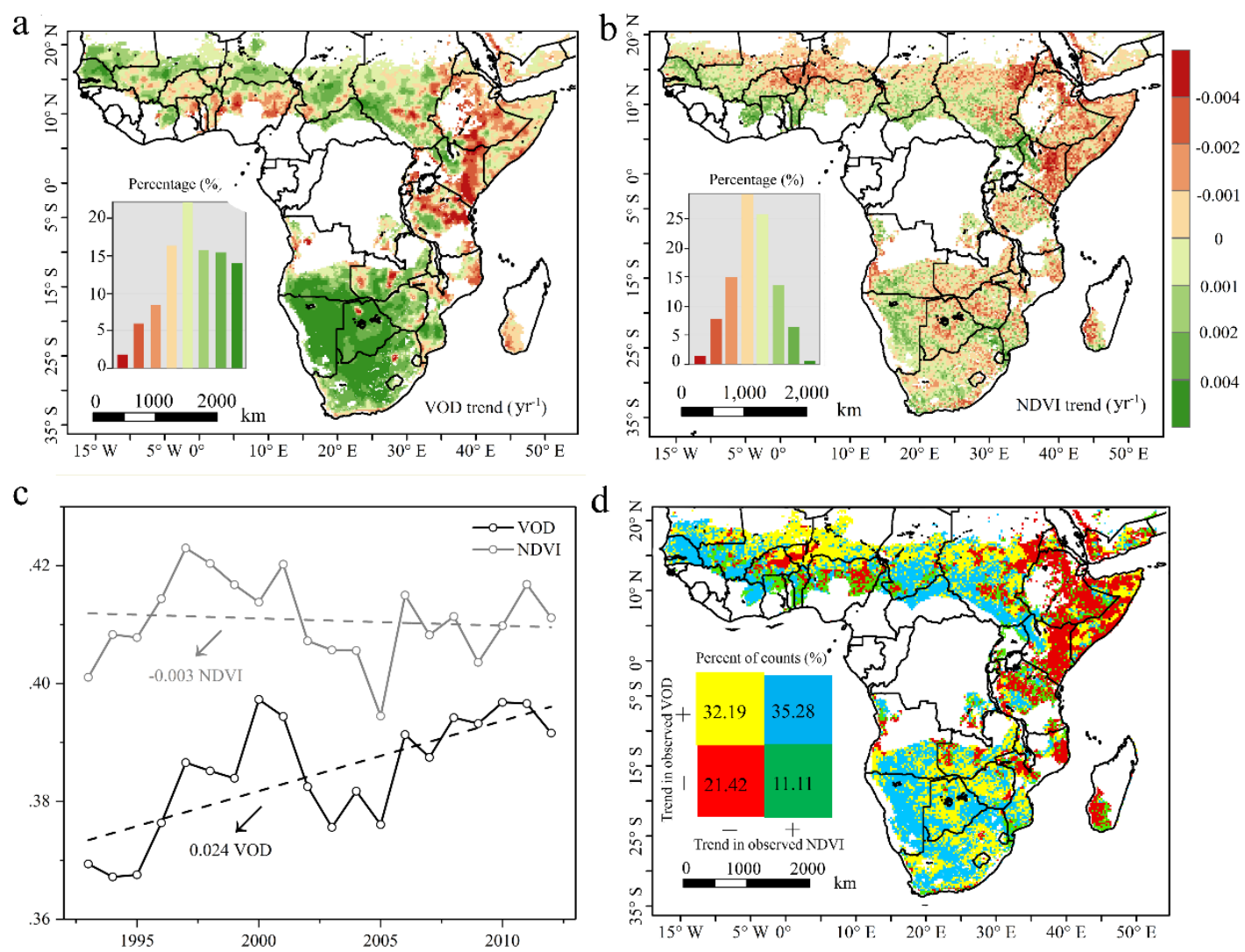

Fig. 1 Spatio-temporal changes of the observed NDVI and VOD and their co-relationship during 1993-2012: (a) VOD; (b) NDVI; (c) changes of annual mean NDVI/VOD for all vegetated African drylands; (d) co-relationship of NDVI and VOD trends divided into four classes $(\mathrm{p}<0.05)$. 


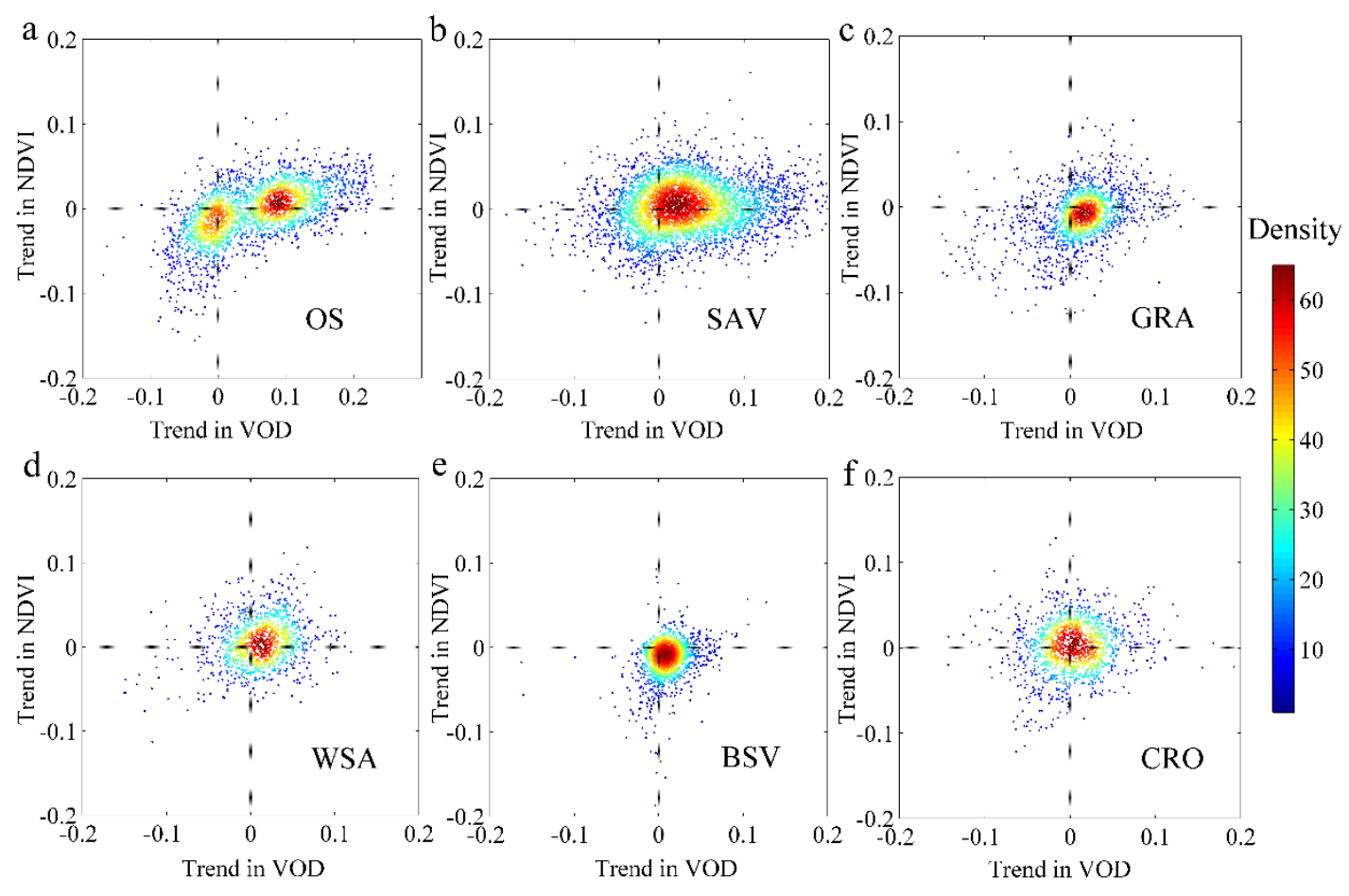

Fig. 2 Spatial agreement of areas with changes in VOD and areas with changes in NDVI for different land cover types. (a) Open shrublands (OS); (b) Savannas (SAV); (c) Grasslands (GRA); (d) Woody savannas (WSA); (e) Barren and sparsely vegetated (BSV); (f) Cropland (CRO). 

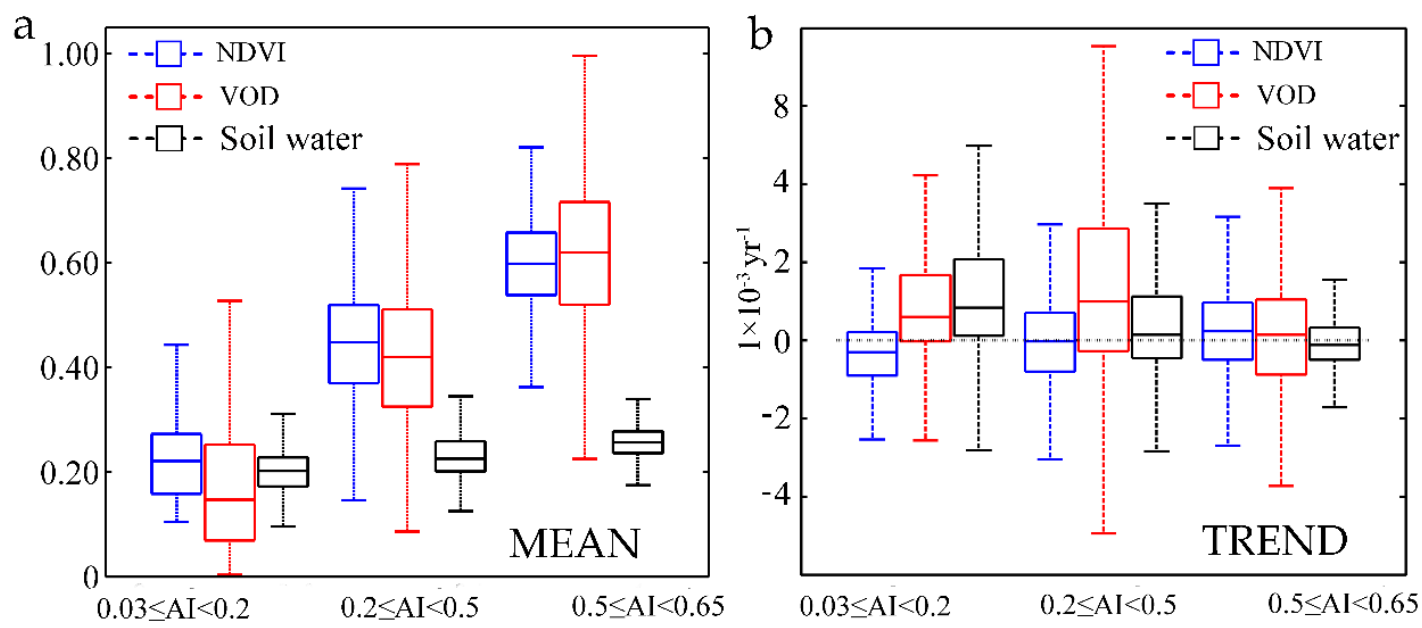

Fig. 3 Box plots of the distribution of annual mean NDVI, VOD, and soil water classified by aridity classes (a). Box plots of the distribution of observed linear trends for NDVI, VOD, and soil water classified by aridity classes (b). The maximum and minimum extents of the colored boxes indicate the 25 th and 75 th percentiles and the whiskers represent the 5th and 95th percentiles. 

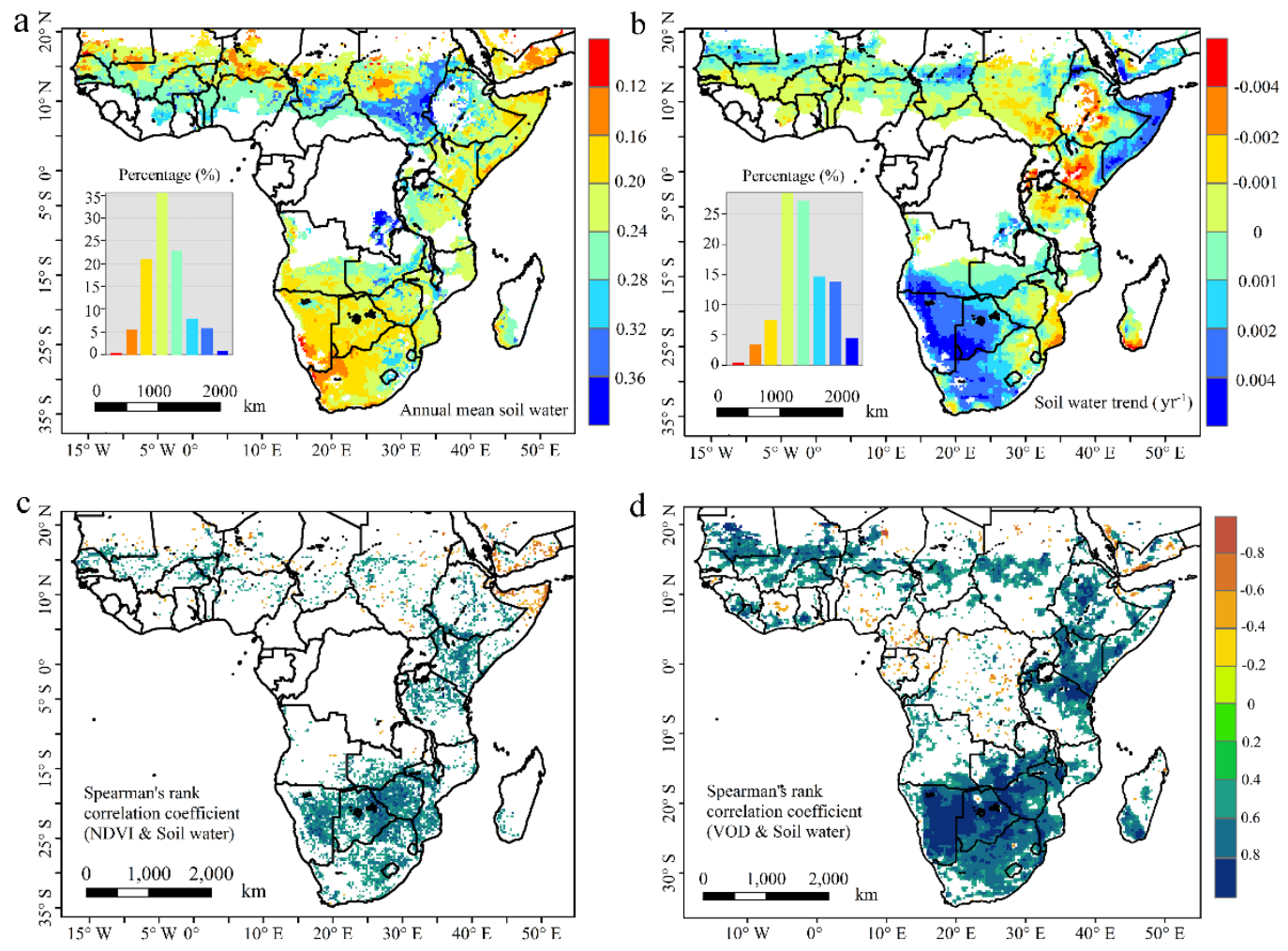

Fig. 4 Spatial patterns of the annual mean value of soil water (a) and (b) the trends during 19932012. Correlations (c) between soil water and NDVI and (d) between soil water and VOD. 


\section{Spatial pattern}

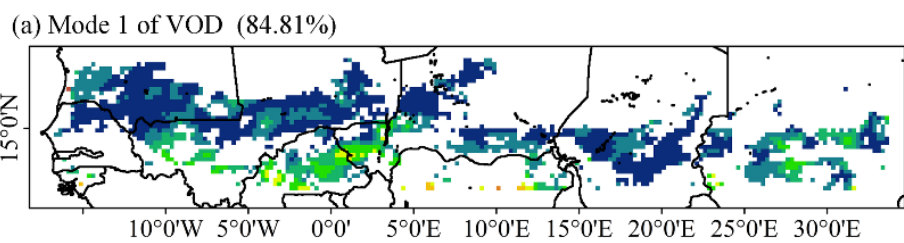

(b) Mode 1 of soil water $(84.81 \%)$

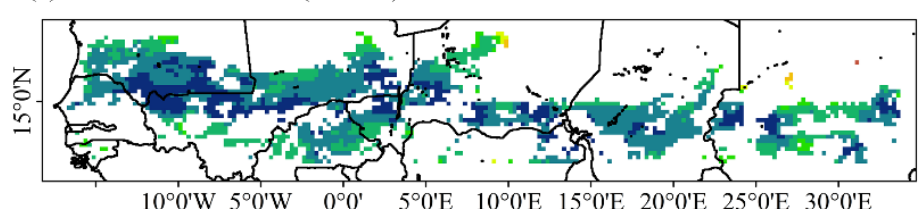

(d) Mode 1 of VOD $(82.66 \%)$

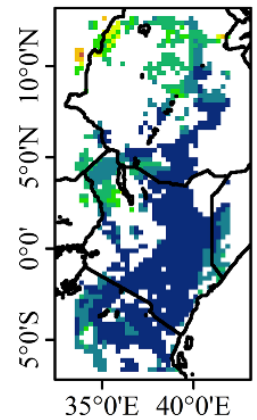

(g) Mode 1 of VOD $(89.76 \%)$

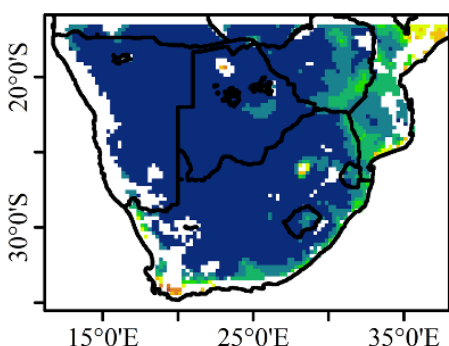

(h) Mode 1 of soil water $(89.76 \%)$

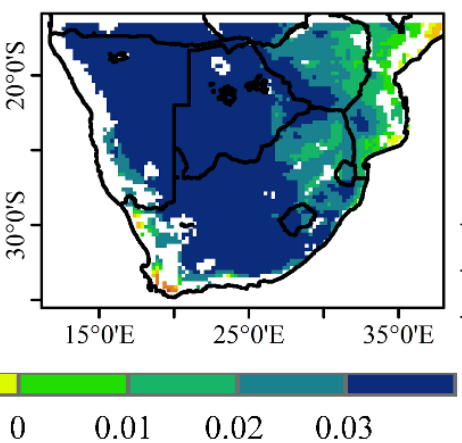

(e) Mode 1 of soil water $(82.66 \%)$

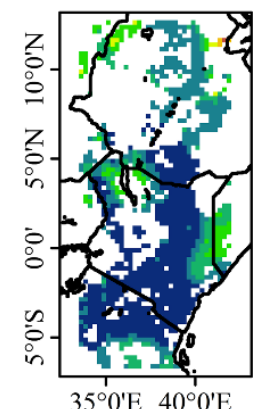

Temporal pattern

(Mode 1)

(c) $\mathrm{R}=0.83$

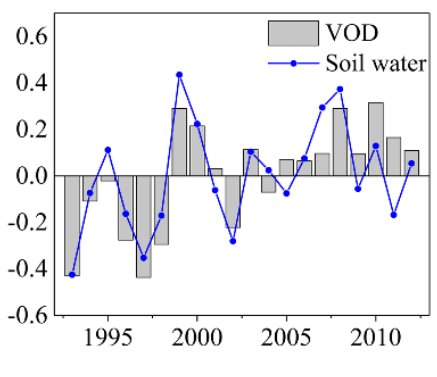

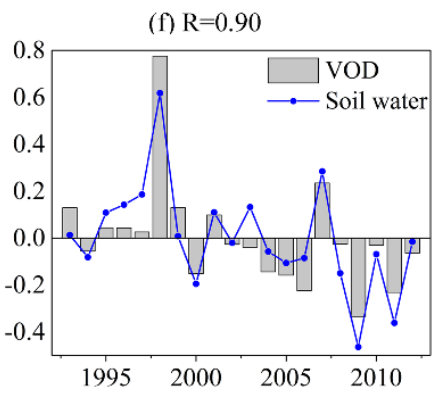

(i) $\mathrm{R}=0.91$

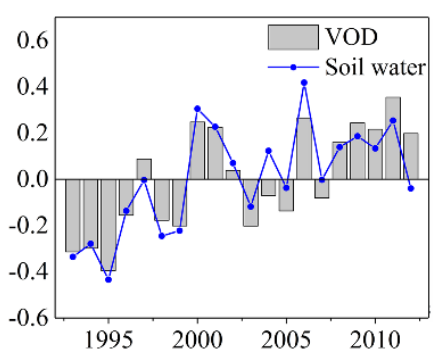

Fig. 5 Spatial patterns (left column) and time series (right column) of the first singular value decomposition mode between VOD and soil water for the period of 1993-2012 in the three sub regions indicated by the dashed black boxes in Fig. S1: west and central Africa (a-c), eastern Africa (d-f) and southern Africa (g-i). 

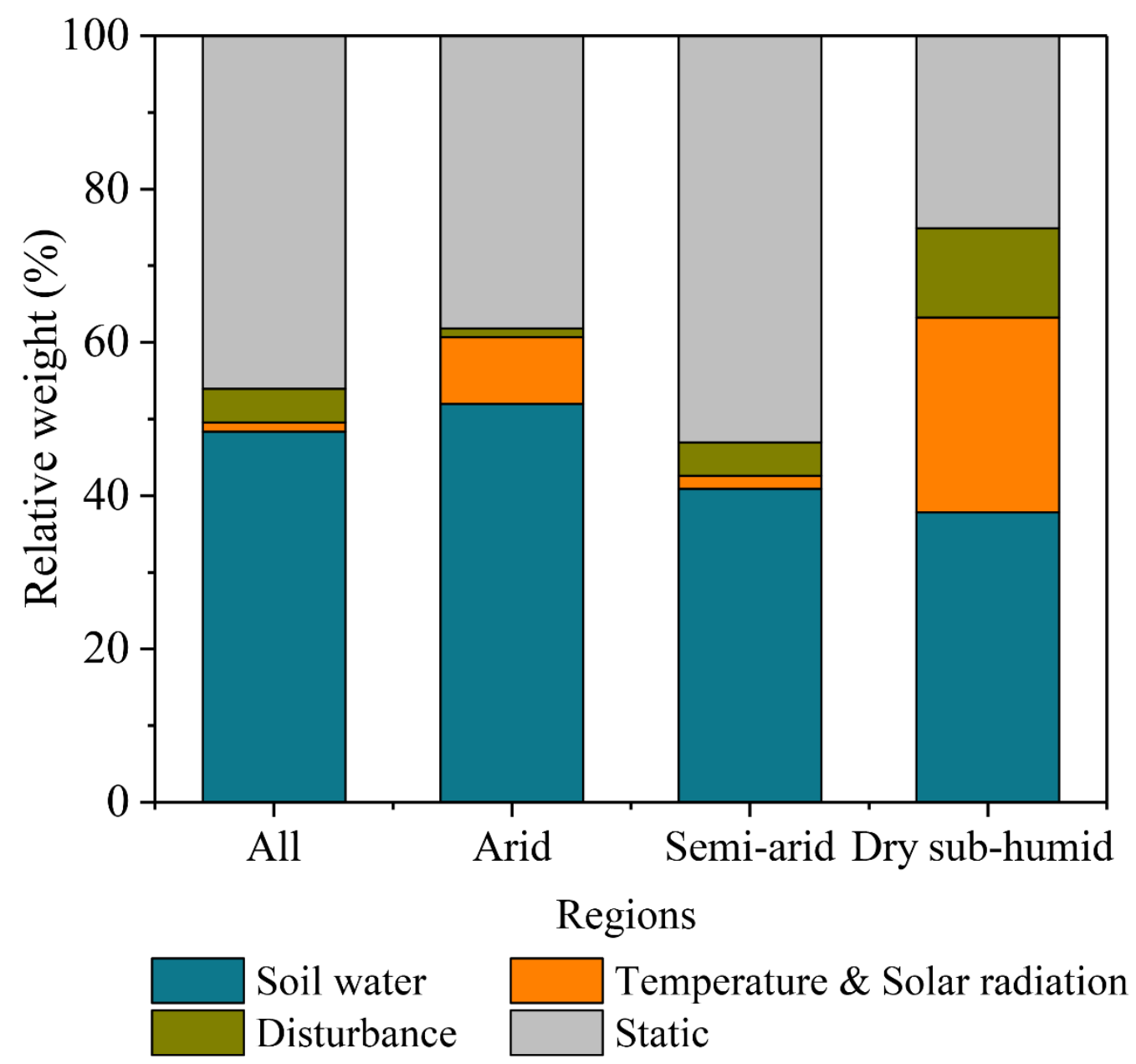

Fig. 6 Relative importance of controlling factors explaining changes in VOD $(1993$ - 2012) from the LMG method based on a least square regression model. Explanatory variables are: change in soil water $\left(\mathrm{mm} / \mathrm{mm} \mathrm{yr}^{-1}\right)$; change in temperature $\left(\mathrm{K} \mathrm{yr}^{-1}\right)$ and solar radiation $\left(\mathrm{W} \mathrm{m}^{-2} \mathrm{yr}^{-1}\right)$; disturbance includes change in population (person $\left.\mathrm{km}^{-2}\right)$ and burned area fraction $\left(\% \mathrm{yr}^{-2}\right)$; Static variables include: mean annual rainfall $\left(\mathrm{mm} \mathrm{yr}^{-1}\right)$; soil organic carbon (SOC); Sand fraction (\%); and elevation (m). 


\section{Supplementary material}

Data availability

GIMMS 3g NDVI data are available at https://ecocast.arc.nasa.gov/data/pub/gimms/. The VOD data is provided by Y. Liu, Nanjing University of Information Science \& Technology, China. GLDAS datasets (including temperature, precipitation, solar radiation, and soil water) are available at https://disc.gsfc.nasa.gov/datasets/. The Gridded Population of the World data can be downloaded from http://sedac.ciesin.columbia.edu/data/collection/gpw-v4. The GFED4s datasets are available at http://www.globalfiredata.org/data.html. The HWSD v1.2 soil maps are available at http://worldgrids.org/doku.php/wiki:layers. GMTED 2010 elevation data is available at http://www.temis.nl/data/gmted2010/index.html. 

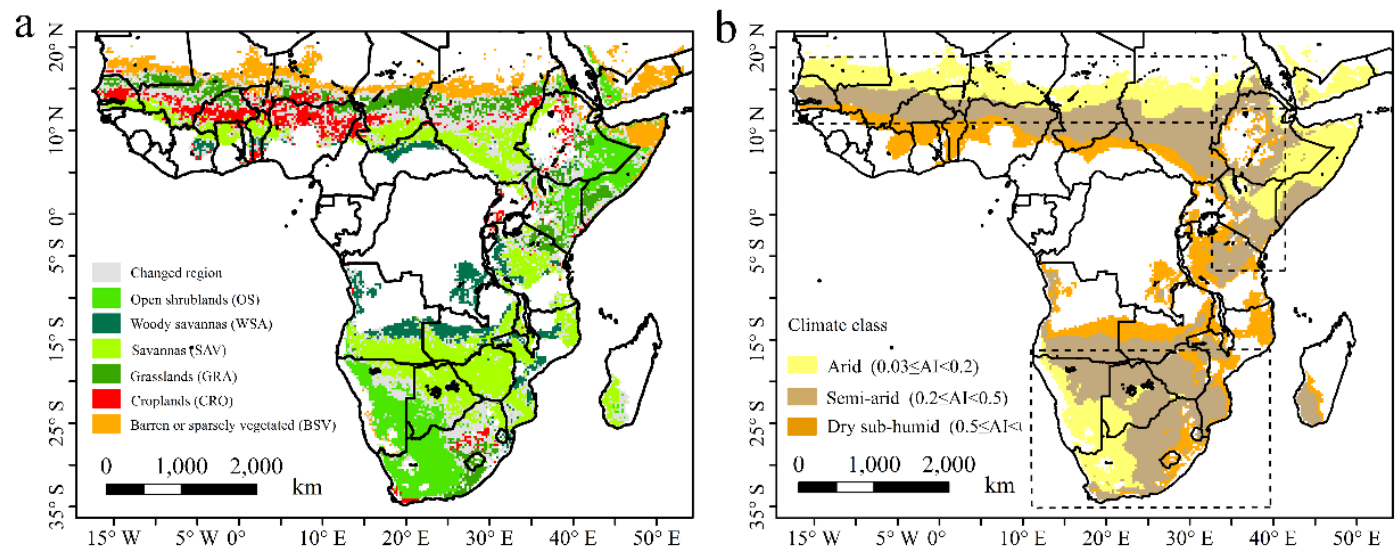

Fig. S1 Land cover and aridity maps: (a) land cover map derived from MODIS MCD12C1 products for 2001-2012; (b) aridity classes based on Global Aridity Index datasets (UNEP, 1997). The areas indicated by the dashed black boxes are further analyzed in Fig. 4, Fig. 5 and Fig. S5 
$\mathrm{a}$

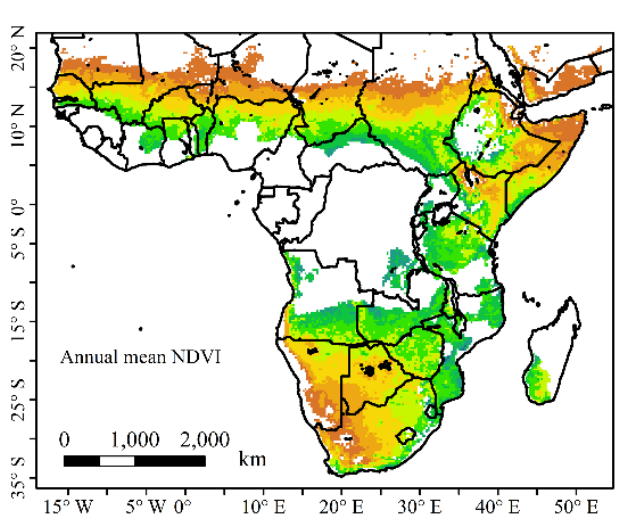

C

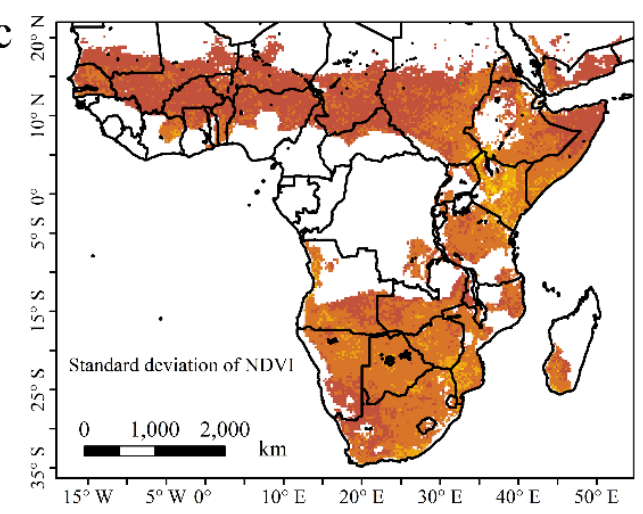

b
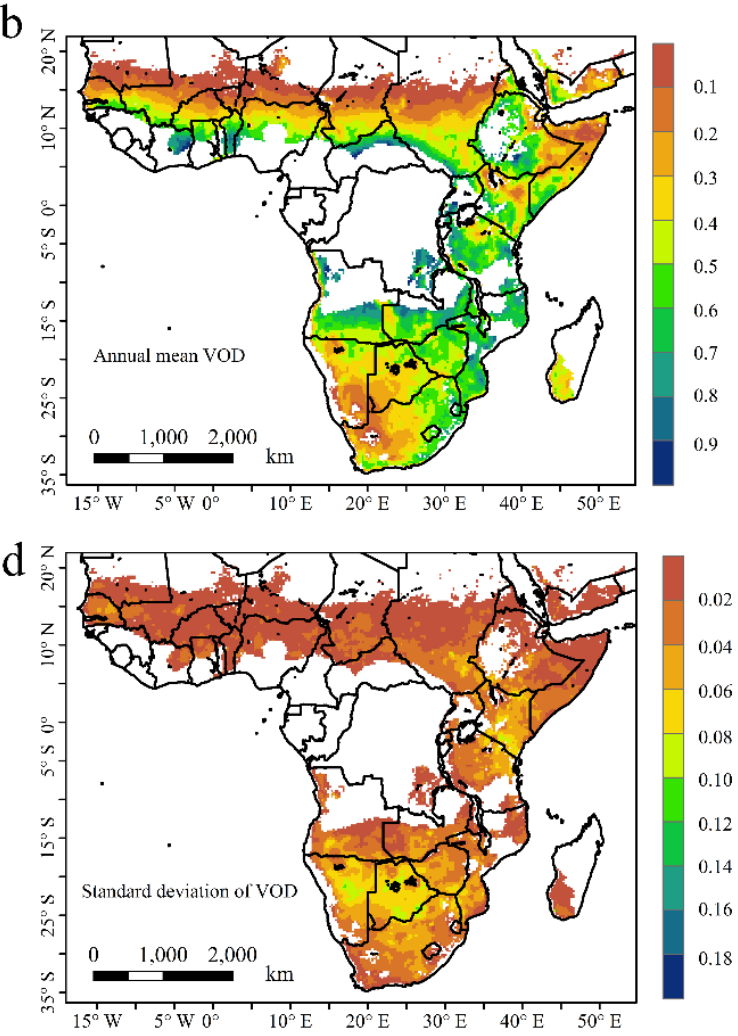

Fig. S2 Spatial patterns of the mean and standard deviation of vegetation indices (1993-2012). (a) mean NDVI; (b) mean VOD; (c) standard deviation of NDVI; (d) standard deviation of VOD. 

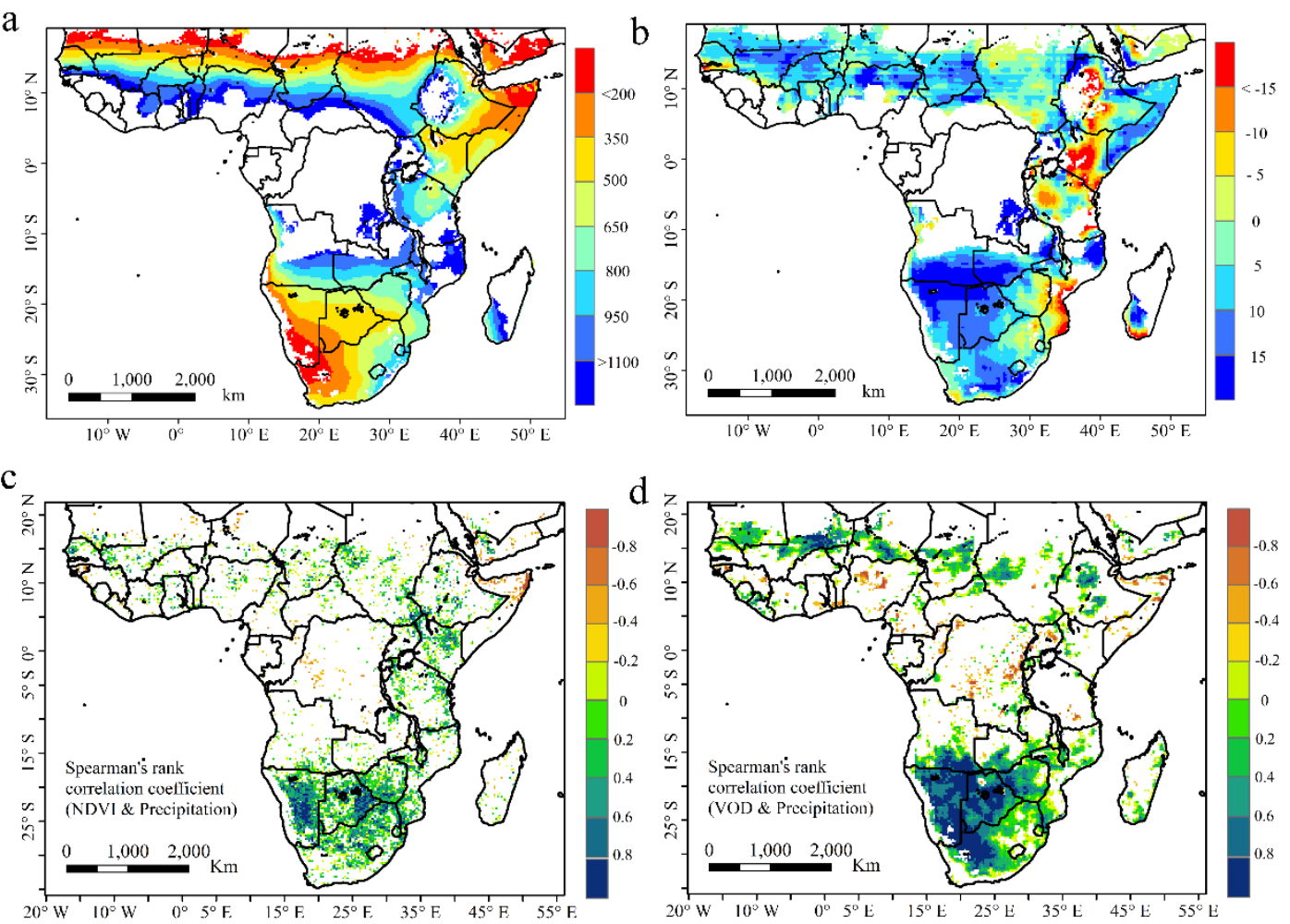

Fig. S3 Spatial patterns of the annual mean value of precipitation (a) and (b) the trends during 19932012. Correlations (c) between precipitation and NDVI and (d) between precipitation and VOD. 


\section{Spatial pattern}

(a) Mode 1 of NDVI $(85.56 \%)$

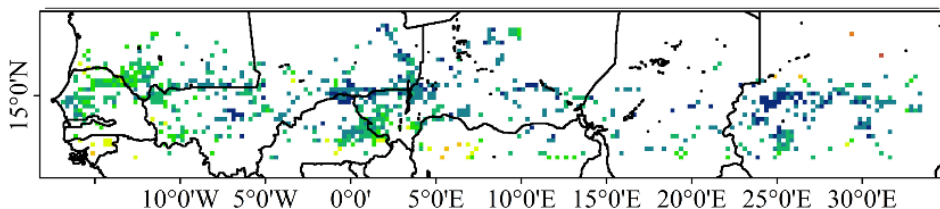

(b) Mode 1 of soil water $(85.56 \%)$

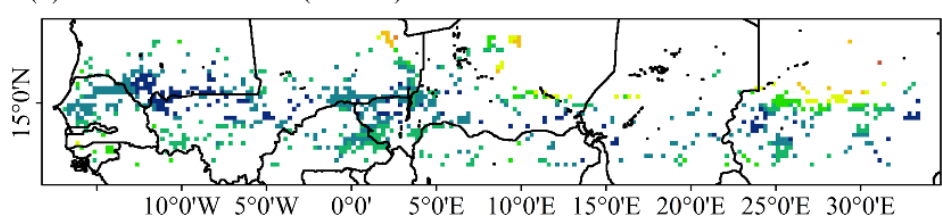

(d) Mode 1 of NDVI $(84.88 \%)$

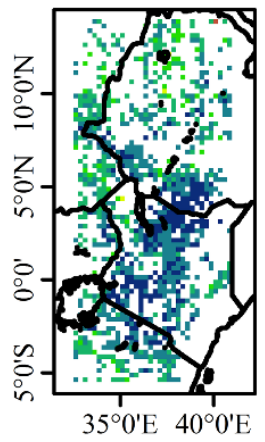

(g) Mode 1 of NDVI $(86.23 \%)$

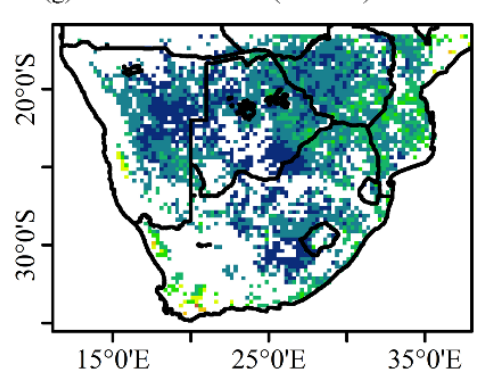

(e) Mode 1 of soil water $(84.88 \%)$

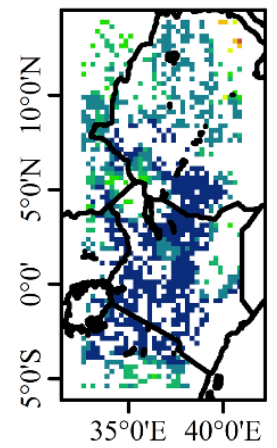

(h) Mode 1 of soil water $(86.23 \%)$

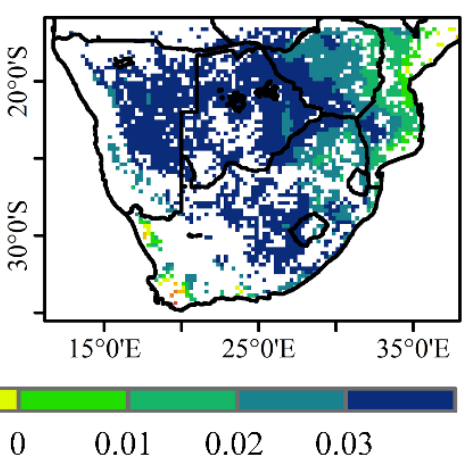

\section{Temporal pattern}

(Mode 1)

(c) $\mathrm{R}=0.32$

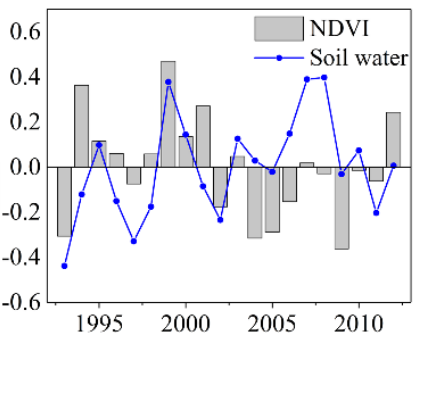

(f) $\mathrm{R}=0.88$

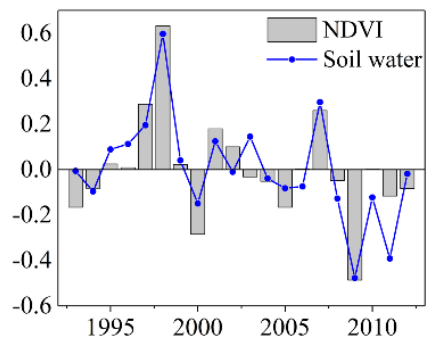

(i) $\mathrm{R}=0.66$

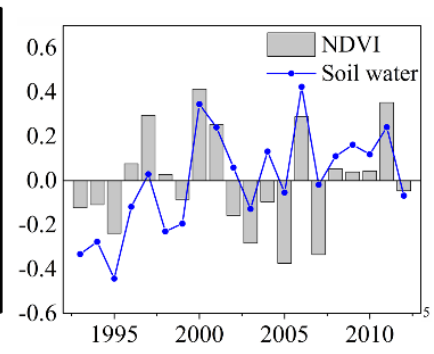

Fig. S4 Spatial patterns (left column) and time series (right column) of the first singular value decomposition mode between NDVI and soil water for the period of 1993-2012 in three sub regions indicated by the dashed black boxes in Fig. S1b: west and central Africa (a-c), eastern Africa (d-f) and southern Africa (g-i). 


\section{Spatial pattern}

(a) Mode 1 of VOD $(74.33 \%)$

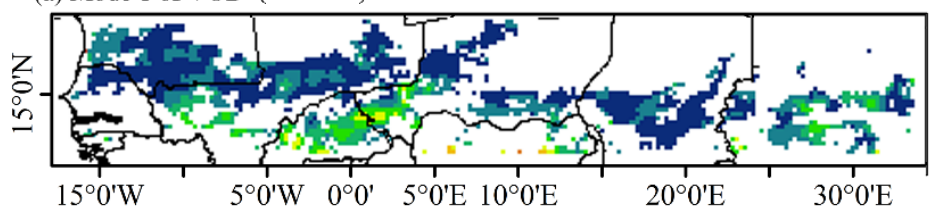

(b) Mode 1 of Rainfall $(74.33 \%)$

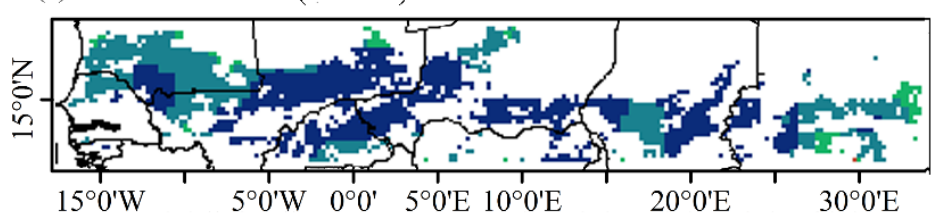

(d) Mode 1 of VOD $(73.66 \%)$

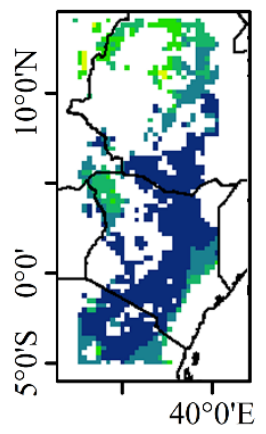

(g) Mode 1 of VOD (89.12\%)

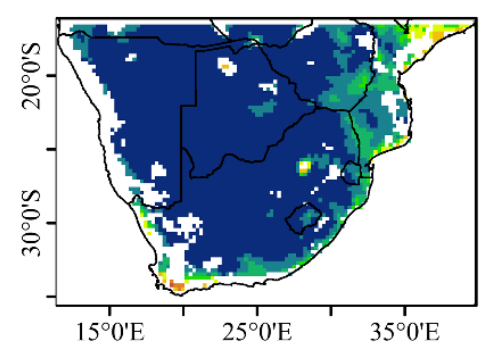

(h) Mode 1 of Rainfall (89.12\%)

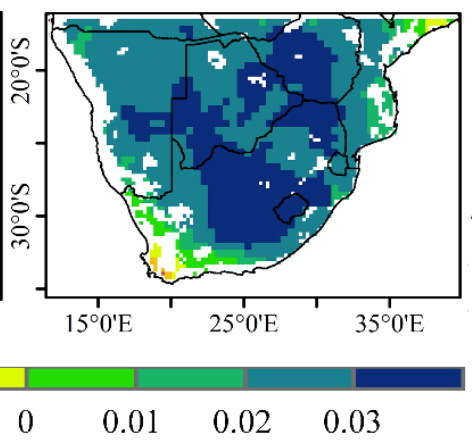

(e) Mode 1 of Rainfall $(73,66 \%)$

\section{$\begin{array}{lllllll}-0.03 & -0.02 & -0.01 & 0 & 0.01 & 0.02 & 0.03\end{array}$}

Temporal pattern

(Mode 1)

(c) $\mathrm{R}=0.57$

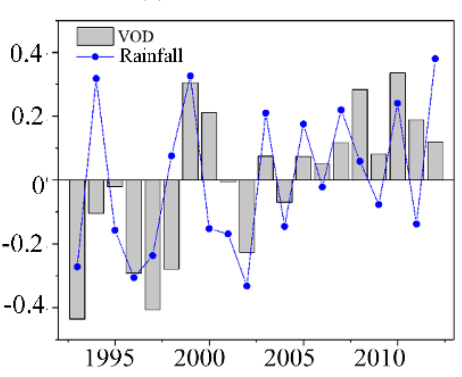

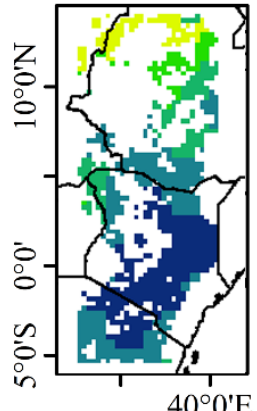

(f) $\mathrm{R}=0.12$

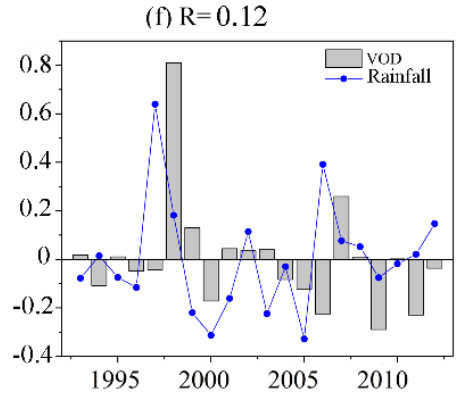

(i) $\mathrm{R}=0.80$

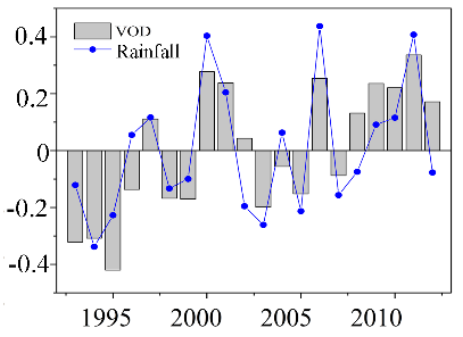

Fig. S5 Spatial patterns (left column) and time series (right column) of the first singular value decomposition mode between VOD and rainfall for the period of 1993-2012 in three sub regions indicated by the dashed black boxes in Fig. S1b: west and central Africa (a-c), eastern Africa (d-f) and southern Africa (g-i). 


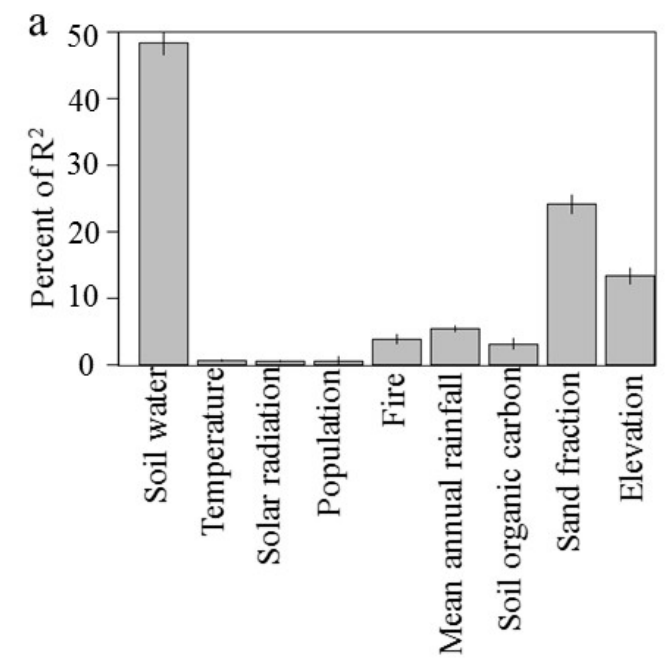

Variables

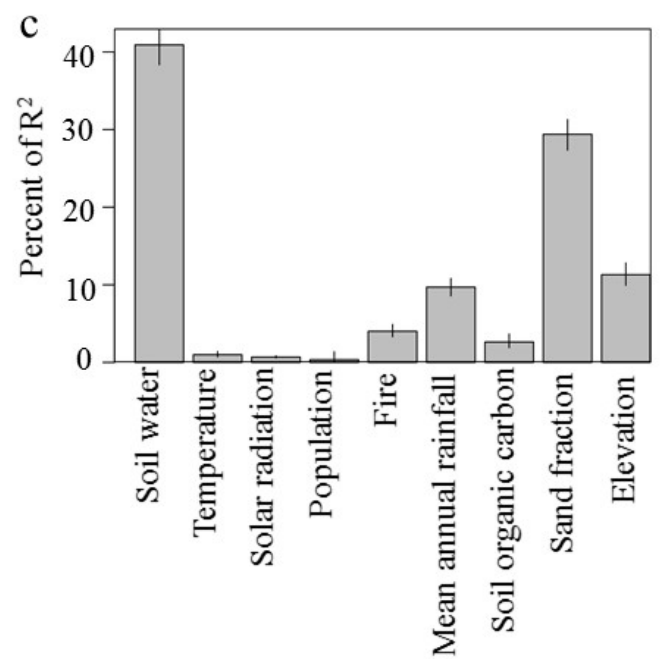

Variables

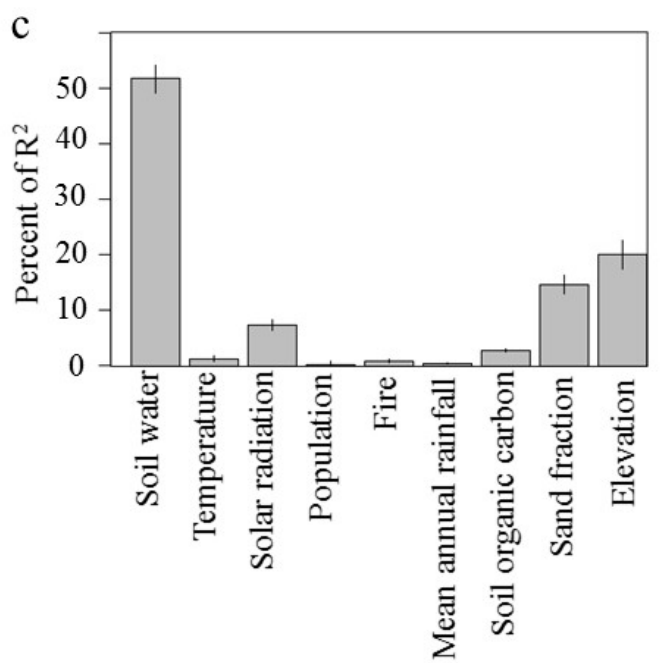

Variables

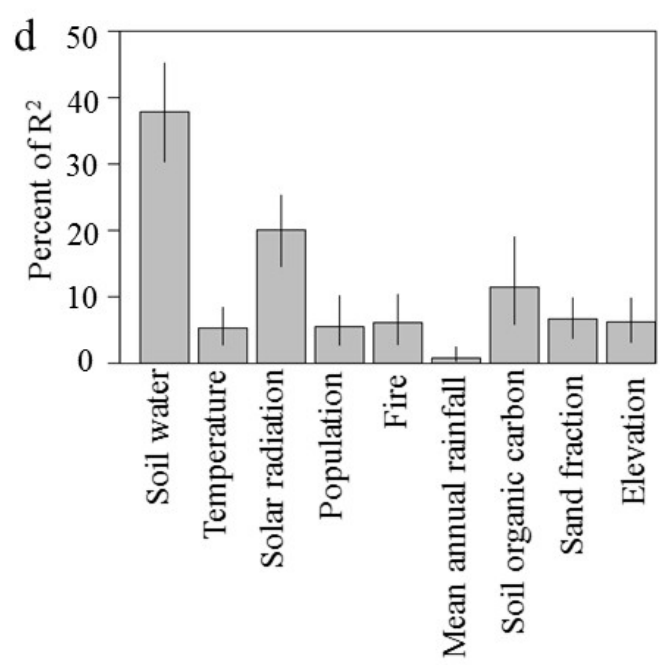

Variables

Fig. S6 Relative contribution of controlling factors to changes in VOD from LMG method based on a least squares regression method. The black line is the standard deviation. Response variable is $\operatorname{VOD}\left(\mathrm{yr}^{-1}\right)$. Explanatory variables are: change in soil water $\left(\mathrm{mm} / \mathrm{mm} \mathrm{yr}^{-1}\right)$; change in temperature $\left(\mathrm{K} \mathrm{yr}^{-1}\right)$, change in solar radiation $\left(\mathrm{W} \mathrm{m}^{-2} \mathrm{yr}^{-1}\right)$; change in population (person $\left.\mathrm{km}^{-2}\right)$, change in burned area fraction $\left(\% \mathrm{yr}^{-2}\right)$; mean annual rainfall $\left(\mathrm{mm} \mathrm{yr}^{-1}\right)$, soil organic carbon (SOC), Sand fraction (\%), elevation $(\mathrm{m})$. The overall explaining power $\left(\mathrm{R}^{2}\right)$ of the model can be found in Table. S3 

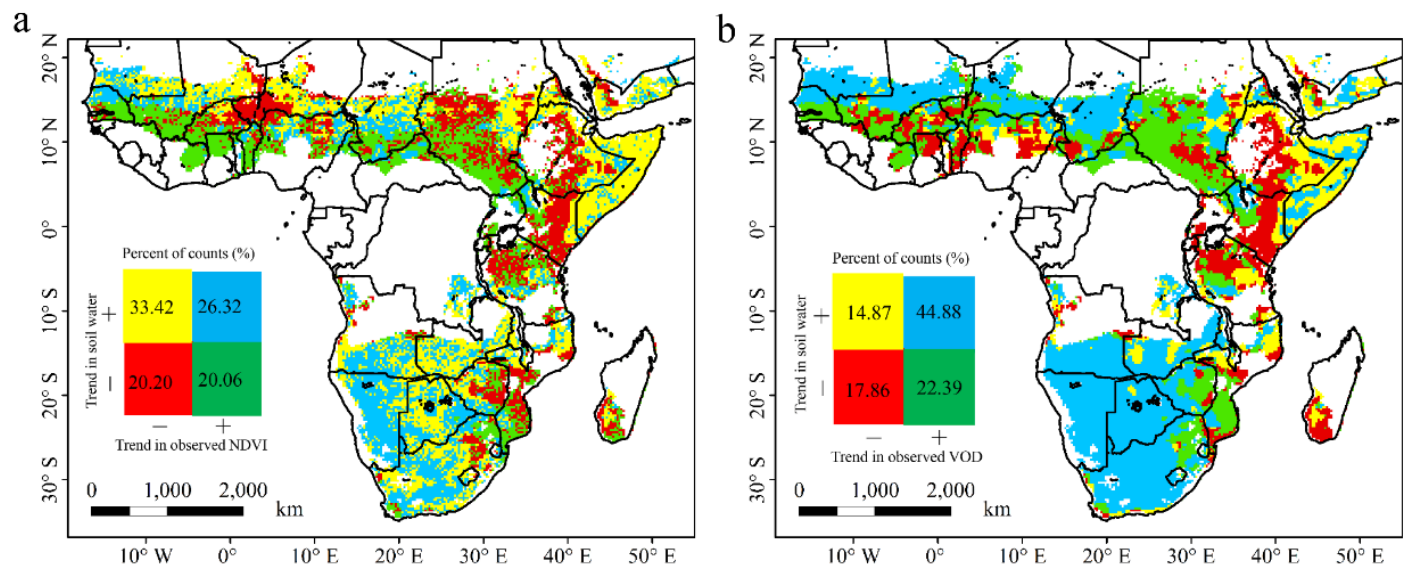

Fig. S7 Spatial agreement of trends in soil water and observed NDVI value (a); spatial agreement of trends in soil water and observed VOD value (b). 
Table. S1 MCD12C1 International Geosphere-Biosphere Programme (IGBP) legend and class descriptions (Friedl et al. 2015).

\begin{tabular}{|c|l|l|}
\hline Value & Name & Description \\
\hline 7 & Open Shrublands & Dominated by woody perennials $(1-2 \mathrm{~m}$ height $) 10-60 \%$ cover. \\
\hline 8 & Woody savannas & Tree cover $30-60 \%$ (canopy $>2 \mathrm{~m})$. \\
\hline 9 & Savannas & Tree cover $10-30 \%$ (canopy $>2 \mathrm{~m})$. \\
\hline 10 & Grasslands & Dominated by herbaceous annuals $(<2 \mathrm{~m})$. \\
\hline 12 & Croplands & At least $60 \%$ of area is cultivated cropland. \\
\hline 14 & $\begin{array}{l}\text { Cropland/Natural } \\
\text { Vegetation Mosaics }\end{array}$ & $\begin{array}{l}\text { Mosaics of small-scale cultivation } 40-60 \% \text { with natural tree, } \\
\text { shrub, or herbaceous vegetation. }\end{array}$ \\
\hline 16 & $\begin{array}{l}\text { Barren or Sparsely } \\
\text { Vegetated }\end{array}$ & $\begin{array}{l}\text { At least } 60 \% \text { of area is non-vegetated barren (sand, rock, soil) } \\
\text { areas with less than } 10 \% \text { vegetation. }\end{array}$ \\
\hline
\end{tabular}

Friedl, M., Sulla-Menashe, D. (2015). MCD12C1 MODIS/Terra+Aqua Land Cover Type Yearly L3 Global 0.05Deg CMG V006 [Data set]. NASA EOSDIS Land Processes DAAC. doi: 10.5067/MODIS/MCD12C1.006 
Table. S2 Variance Inflation Factor (VIF) values for the explanatory variables to test for multicollinearity. VIF $<5$ means no multicollinearity among explanatory variables whereas VIF $>5$ indicate multicollinearity among explanatory variables. The study area is divided into African drylands (All) and its sub-regions including arid $(0.03 \leqslant \mathrm{AI}<0.2)$, semi-arid $(0.2 \leqslant \mathrm{AI}<0.5)$ and dry sub-humid regions $(0.5 \leqslant \mathrm{AI}<0.65)$. Response variable is VOD $\left(\mathrm{yr}^{-1}\right)$. Explanatory variables are: change in soil water $\left(\mathrm{mm} / \mathrm{mm} \mathrm{yr}^{-1}\right)$; change in temperature $\left(\mathrm{K} \mathrm{yr}^{-1}\right)$, change in solar radiation ( $\left.\mathrm{W} \mathrm{m}^{-2} \mathrm{yr}^{-1}\right)$; change in population (person $\mathrm{km}^{-2}$ ), change in burned area fraction $\left(\% \mathrm{yr}^{-2}\right)$; mean annual rainfall $\left(\mathrm{mm} \mathrm{yr}^{-1}\right)$, soil organic carbon (SOC), Sand fraction (\%), elevation (m). N indicates the number of pixels in each of the regions analyzed.

\begin{tabular}{|l|c|c|c|c|}
\hline \multirow{2}{*}{\multicolumn{1}{c|}{ VIF values }} & All & $\begin{array}{c}\text { Arid } \\
(\mathbf{0 . 0 3} \leq \mathbf{A I}<\mathbf{0 . 2})\end{array}$ & $\begin{array}{c}\text { Semi-arid } \\
(\mathbf{0 . 2} \leq \mathbf{A I}<\mathbf{0 . 5})\end{array}$ & $\begin{array}{c}\text { Dry sub-humid } \\
(\mathbf{0 . 5} \leq \mathbf{A I}<\mathbf{0 . 6 5})\end{array}$ \\
\cline { 2 - 5 } & $\mathrm{N}=16729$ & $\mathrm{~N}=5198$ & $\mathrm{~N}=7936$ & $\mathrm{~N}=3595$ \\
\hline Change in soil water & 1.3787 & 1.2466 & 1.4514 & 1.0918 \\
\hline Change in temperature & 1.3427 & 1.0944 & 1.2095 & 1.2683 \\
\hline Change in solar radiation & 1.105 & 1.1602 & 1.0863 & 1.0658 \\
\hline Change in population & 1.0067 & 1.0111 & 1.0063 & 1.0099 \\
\hline Change in burned area fraction & 1.092 & 1.0717 & 1.1107 & 1.1042 \\
\hline Mean rainfall & 1.5961 & 1.1236 & 1.4474 & 1.2643 \\
\hline Soil organic carbon & 1.106 & 1.5906 & 1.0833 & 1.0798 \\
\hline Sand fraction & 1.2111 & 1.686 & 1.2947 & 1.1454 \\
\hline Elevation & 1.1071 & 1.3153 & 1.2668 & 1.4313 \\
\hline
\end{tabular}


Table S3 The overall explaining power $\left(\mathrm{R}^{2}\right)$ of a least squares regression model to explain changes in VOD for African drylands (All) and its sub-regions including arid $(0.03 \leqslant \mathrm{AI}<0.2)$, semi-arid $(0.2 \leqslant \mathrm{AI}<0.5)$ and dry sub-humid regions $(0.5 \leqslant \mathrm{AI}<0.65)$, with explanatory variables identical to Fig. S6.

\begin{tabular}{|c|c|c|c|c|c|c|c|c|}
\hline \multirow{2}{*}{ Models } & \multicolumn{2}{|c|}{ All } & \multicolumn{2}{c|}{$\begin{array}{c}\text { Arid } \\
(\mathbf{0 . 0 3} \leqslant \mathbf{A I}<\mathbf{0 . 2})\end{array}$} & \multicolumn{2}{c|}{$\begin{array}{c}\text { Semi-arid } \\
(\mathbf{0 . 2} \leqslant \mathbf{A I}<\mathbf{0 . 5})\end{array}$} & \multicolumn{2}{c|}{$\begin{array}{c}\text { Dry sub-humid } \\
(\mathbf{0 . 5} \leqslant \mathbf{A I}<\mathbf{0 . 6 5})\end{array}$} \\
\cline { 2 - 9 } & $\mathbf{N}$ & $\mathbf{R 2}$ & $\mathbf{N}$ & $\mathbf{R 2}$ & $\mathbf{N}$ & $\mathbf{R 2}$ & $\mathbf{N}$ & $\mathbf{R 2}$ \\
\hline Least squares model & 16729 & 0.37 & 5198 & 0.52 & 7936 & 0.43 & 3595 & 0.14 \\
\hline
\end{tabular}

